\title{
Experimental and numerical study on the perforation process of mild steel sheets subjected to perpendicular impact by hemispherical projectiles
}

\author{
A. Rusinek ${ }^{\mathrm{a}, *}$, J.A. Rodríguez-Martínez ${ }^{\mathrm{b}}$, R. Zaera $^{\mathrm{b}}$, J.R. Klepaczko $^{\mathrm{c}}$, A. Arias $^{\mathrm{b}}$, C. Sauvelet $^{\mathrm{c}}$ \\ a National Engineering School of Metz (ENIM), Laboratory of Mechanical Reliability (LFM), Ile du Saulcy, 57000 Metz, France \\ ${ }^{\mathrm{b}}$ Department of Continuum Mechanics and Structural Analysis, University Carlos III of Madrid, Avda. de la Universidad 30, 28911 Leganés, Madrid, Spain \\ ${ }^{\mathrm{c}}$ Laboratory of Physic and Mechanic of Materials, UMR CNRS 75-54, University Paul Verlaine of Metz, Ile du Saulcy, 57045 Metz Cedex, France
}

\begin{abstract}
A B S T R A C T
In this paper a study is presented on the experimental and numerical analysis of the failure process of mild steel sheets subjected to normal impact by hemispherical projectiles. The experiments have been performed using a direct impact technique based on Hopkinson tube as a force measurement device. The tests covered a wide range of impact velocities. Both lubricated and dry conditions between specimen and projectile have been applied. Different failure modes for each case were found. For lubricated conditions a petalling was observed, whereas for dry conditions a radial neck along with a hole enlargement reduces the formation of petalling. The perforation process has been simulated by the application of 3D analysis using ABAQUS/Explicit FE code. The material behavior of the circular specimen was approximated by three different constitutive relations. The main task was to study the influence of the material definition on the response of the sheet specimen with special attention to the failure mode.
\end{abstract}

\section{Introduction}

The response of materials under dynamic loading has a consid erable interest. It allows for clarification of several problems in different application fields such as civil, military, aeronautical and automotive engineering. In particular, many studies on the behavior of steels subjected to high strain rate concentrated in the past a large amount of efforts [1 9 ].

The extreme case of a material subjected to high strain rate solicitation is generally observed during impact or explosion. Thus, in many cases the strain rate level observed in a structure can be higher than $\dot{\varepsilon} \geq 10^{4} \mathrm{~s}^{-1}$. In addition, it is observed locally a strong temperature increase by adiabatic heating which triggers a thermal softening of material.

A special interest has been focused on the perforation resulting from an impact between non deformable projectiles and metallic plates [10 18]. During such kind of impact loading, petalling as

\footnotetext{
* Corresponding author. Tel.: +33 3873150 20; fax: +33 387344279.

E-mail address: rusinek@enim.fr (A. Rusinek).
}

a failure mode commonly appears when ogival, conical or hemi spherical projectiles are applied [1923].

The failure mode seems to be strongly dependent on the impact velocity. Petalling can be replaced by failure mode of crack opening when impact velocity is close to the ballistic limit. In this situation a decrease of the circumferential strain slows the crack progression [22]. Moreover, when the impact velocity is very high, the perfo ration process is governed by inertia effects and the failure mode changes from petalling to complete fragmentation of the zone affected by impact, inducing appearance of debris cloud as final stage [10,24]. Teng et al. [7] have also observed the influence of the impact velocity on the failure mode during Taylor tests performed with Weldox 460 E steel cylinders. At relatively low impact velocity no external cracks appeared in the specimen impacted. On the contrary, for high initial impact velocity it was observed the formation of several radial cracks. They were rapidly propagated causing formation of petals.

Therefore, to define properly the transition between these different failure modes appearing when hemispherical projectiles are used, it is necessary to define precisely the behaviour of the material. All these processes are strongly depend upon strain 


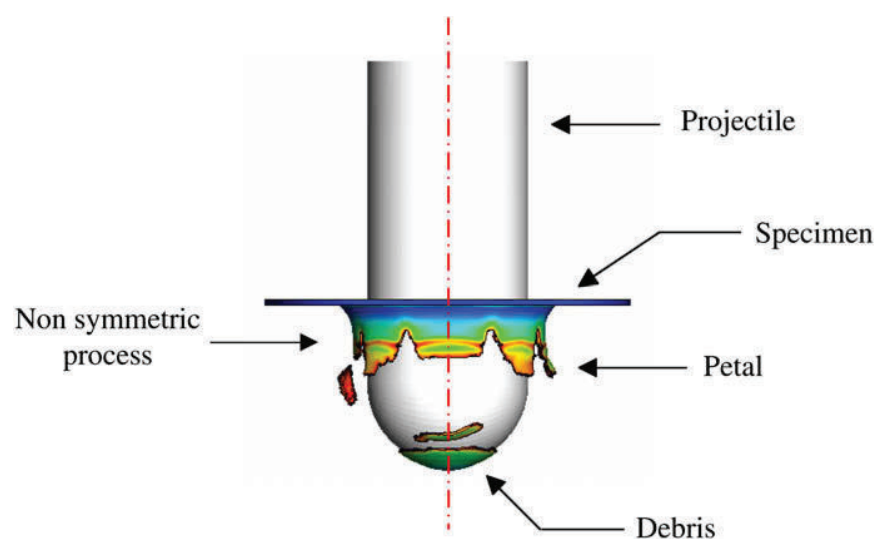

Fig. 1. Perforation process by 3D numerical approach, visualization of petalling phenomenon.

hardening $\bar{\varepsilon}_{\mathrm{p}}$, strain rate $\dot{\bar{\varepsilon}}_{\mathrm{p}}$ and temperature increase $T$ responsible of thermal softening.

In order to define the behavior of steel under dynamic and complex state of stress, several constitutive relations can be found in the international literature [25 32]. A precise analysis concern ing this topic can be found in the works of Liang and Khan [33] and Rusinek et al. [34].

In the present work an experimental and numerical analysis on the impact behavior of sheets of mild steel subjected to perpen dicular impact by hemispherical projectiles is reported. The experiments have been carried out at the Laboratory of Physics and Mechanics of Materials (LPMM) of Metz University using a Hop kinson tube as a transducer to measure the transmitted force [35]. Both lubricated and dry conditions have been applied to the contact between hemispherical projectile and specimen inducing different failure modes for each case. Thus, for lubricated condition petalling process was observed, while the petalling was reduced to a circumferential notch for dry condition.

The finite element code ABAQUS/Explicit has been used to simulate the impact process. An axi symmetric mesh configuration is commonly used to model this kind of penetration problems, mainly in order to reduce large computational time due to small element size required. However, this simplification does not allow reproducing precisely the failure mode discussed previously since petalling is not a symmetric process of failure, Fig. 1. In the present case, the problem was solved by 3D simulations allowing a complete analysis of the problem.

Three constitutive relations, Johnson Cook (JC), Rusinek Kle paczko (RK) and a power law of strain hardening (PL) [36] have been used to define the plastic behavior of material. The use of different constitutive models allows for evaluation of the influence of material's definition on the dynamic response of plates and on the simulation of the failure modes. The analysis has been focused on the failure mode definition depending on dry or lubricated conditions which were applied. A wide range of impact velocities was assumed.

\section{Experimental setup}

To analyze the failure behavior of a steel sheet subjected to normal impact for a maximum velocity of $V_{0}^{\max } \approx 100 \mathrm{~m} / \mathrm{s}$, an original experimental setup has been developed $[35,37,38]$. This experiment is based on the RM Davies bar concept by the appli cation of Hopkinson tube, Fig. 2. With that arrangement it is possible to determine the force $F(t)$ applied to the specimen during perforation process through the measurement of the transmitted elastic wave $\varepsilon_{\mathrm{T}}(t)$

Moreover, black white stripes cemented on the projectile surface enabled to record large displacements imposed onto the steel sheet specimen $\delta_{\mathrm{p}}$ during perforation. The details are given below. Two optical fibers transmit the light and the third one transmits the reflected light from the projectile stripes to a photo diode. A system with three optical fibers coupled with two time counters enables to determine the impact velocity $V_{0}$ at the instant of impact. The acceleration/deceleration of the projectile can be determined with precision. The projectile used in this configuration had a hemispherical shape with a diameter $d_{\mathrm{p}} \quad 22 \mathrm{~mm}$ and a mass $M_{\mathrm{p}} \quad 0.154 \mathrm{~kg}$. The specimen has a thickness $t_{\mathrm{specimen}} 0.8 \mathrm{~mm}$, an effective diameter $\phi_{\text {effective }} 30 \mathrm{~mm}$ and a total diameter $\phi_{\text {specimen }} 50 \mathrm{~mm}$. During the test it is possible to prepare dry or lubricated conditions using, in the last case, several layers of grease and Teflon foil [37].

The time history of the force $F(t)$ transmitted by the specimen support into the tube is defined by the following relation:

$F(t) \quad \frac{\pi E\left(D^{2} d^{2}\right)}{4} \varepsilon_{\mathrm{T}}(t)$

where $E$ is Young's modulus of the tube, $D$ and $d$ are, respectively, the external and internal diameters of the Hopkinson tube (d $\phi_{\text {effective }}$ and $D$ कspecimen).

The displacement imposed during perforation is obtained by decoding the signals from the photodiode in the form of maxima corresponding to the white stripes on the projectile, Fig. 3. The width of white and black stripes can be chosen by the user, typically range from $0.1 \mathrm{~mm}$ to $0.5 \mathrm{~mm}$. This principle is based on the frequency coding of displacement [39].

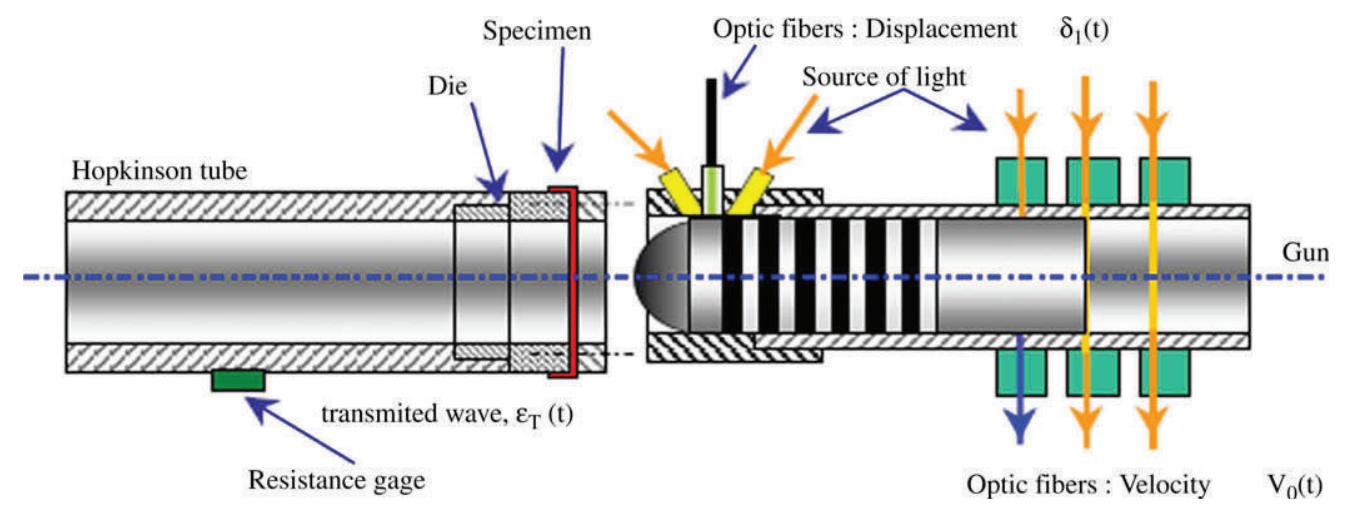

Fig. 2. Scheme of the experimental setup [37]. 


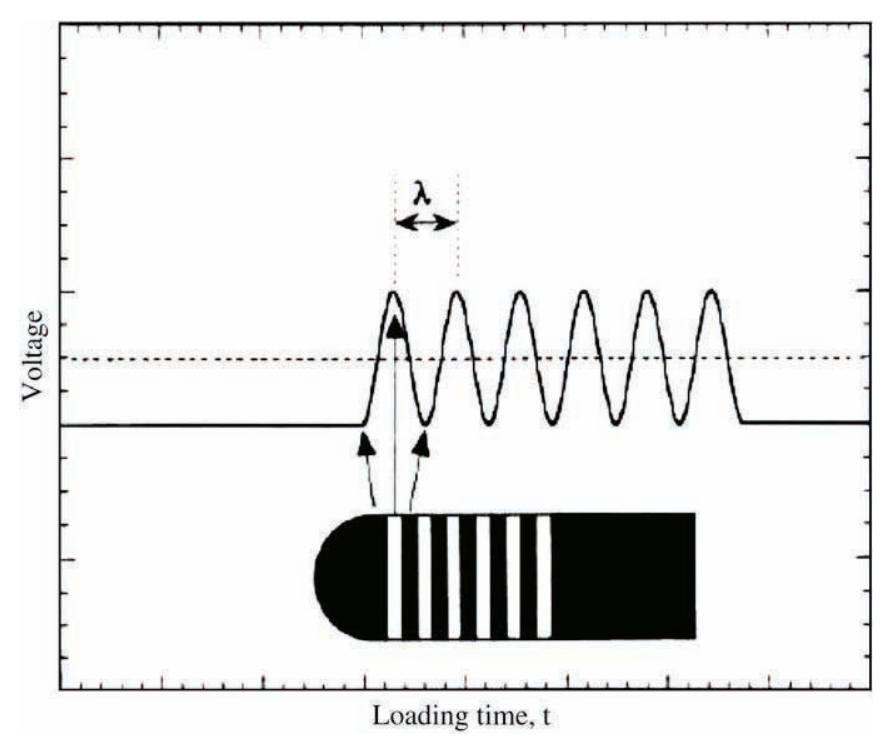

Fig. 3. Scheme of the frequency coding of projectile displacement.

The total displacement is obtained using the following equation, Eq. (2), with the time signal, Fig. 3

$\delta_{\mathrm{p}}(t) \quad n \lambda \quad C_{0} \int_{0}^{t} \varepsilon_{\mathrm{T}}(\varsigma) \mathrm{d} \varsigma$

where $n$ is the number of maxima measured during the process of perforation, Fig. 3 , and $C_{0}$ is the elastic wave velocity in the tube. Details of this experimental technique are reported in Refs. $[35,37,38]$ for low and high velocities using a fast hydraulic machine and a Hopkinson tube technique.

Typical experimental results in the form of specimen pictures and $F(t)$ records are shown in Fig. 4. The cases shown in Fig. 4 are for the impact velocities above the ballistic limit. The comparison shows substantial differences in specimen behavior in terms of failure using dry or lubricated conditions. In the case of dry condition a plug ejection is observed during loading, Fig. 4c.

Experimental results, a numerical study is performed to analyze constitutive relation effect on the failure mode.

\section{Modeling of dynamic behavior of mild steel}

Mild steel ES is a ferritic steel with an average grain size of $\phi \quad 16 \mu \mathrm{m}$. It has a particular interest since many results are avail able in the international literature permitting to identify material constants in any constitutive relation see Appendix A [5,40,41]. The behavior of the mild steel is assumed as a reference since it has been tested by a number of laboratories in recent decades. Typical mild steel assumed in this study is characterized ahead (ES steel). The chemical composition in weight of this material is reported in Table 1. It must be noticed that all specimens used to perform the tests of characterization and perforation were machined from the same plate. Different tests have been performed with this material in tension, shear and perforation at different strain rates, temper atures and loading paths. Using previous experimental results an isotropic behaviour was observed.

To approximate the dynamic behavior of that material several constitutive relations can be used depending on the application and the required information. Thus, in this paper three constitutive relations have been applied: two phenomenological and one semi physical. The goal was to analyze theirs effects on the prediction of the failure process during impact perforation using the same failure criterion.

\subsection{Phenomenological approach $I$}

The first constitutive relation used in this work to analyze the perforation process is a power law (PL) which takes into account strain hardening $\bar{\varepsilon}_{\mathrm{p}}$, strain rate $\dot{\bar{\varepsilon}}_{\mathrm{p}}$ and temperature sensitivity $T$. The explicit formulation of the constitutive relation is defined by

$\bar{\sigma}\left(\bar{\varepsilon}^{\mathrm{p}}, \dot{\bar{\varepsilon}} \mathrm{p}, T\right) \quad B\left(\bar{\varepsilon}_{\mathrm{p}}\right)^{n}\left(\dot{\bar{\varepsilon}}_{\mathrm{p}}\right)^{m} T^{-\nu}$

where $B$ is the material constant characterizing the stress level, $n, m$ and $\nu$ are, respectively, the hardening exponent, strain rate and temperature sensitivities. Although non linear strain rate sensi tivity is considered, this constitutive equation cannot be used within a complete spectrum of strain rates and values of $m$ must be decomposed in several ranges, Fig. 5. Thus, in the present study two different sets of constants have been used, the first one corre sponding to low strain rates (PLI) and the second one to high strain rates (PLII) (Appendix A). To compare FE analyses with application of this simple phenomenological approach, another phenomeno logical approach has been used as it is discussed in the next part of this paper.

\subsection{Phenomenological approach II}

The second thermo visco plastic constitutive relation is the one due to Johnson Cook (JC), frequently applied to analyze the dynamic behavior of materials [15 17,42 44]. This constitutive relation is generally pre implemented in FE codes, including ABA QUS/Explicit. The JC constitutive relation is defined by Eq. (4). The first term defines strain hardening $\bar{\varepsilon}_{\mathrm{p}}$, the second strain rate sensitivity, $\dot{\bar{\varepsilon}}_{\mathrm{p}}$ via the constant $C$ and the third one is related to thermal softening T, Eqs. (4) and (5).

$\bar{\sigma}\left(\bar{\varepsilon}^{\mathrm{p}}, \dot{\bar{\varepsilon}}^{\mathrm{p}}, T\right) \quad\left[A+B\left(\bar{\varepsilon}^{\mathrm{p}}\right)^{n}\right]\left[1+C \ln \left(\frac{\dot{\bar{\varepsilon}}^{\mathrm{p}}}{\dot{\varepsilon}_{0}}\right)\right]\left(\begin{array}{ll}1 & \Theta^{m}\end{array}\right)$

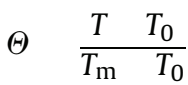

where $A$ and $B$ are material constants, $n$ is the strain hardening exponent, $m$ is the temperature sensitivity, $T_{0}$ is the initial temperature and $T_{\mathrm{m}}$ is the melting temperature.

As this material shows non linear strain rate sensitivity, Fig. 5, it is not possible to define it correctly with one set of parameters by Eq. (4). Thus, the strain rate sensitivity must be defined separately in JC equation in several ranges. In present work, as previously proposed for $\mathbf{P L}$, two ranges have been used, one corresponding to low strain rates $(\mathbf{J C I})$, the second one for high strain rates (JCII) (Appendix A). A comparison is reported in Fig. 5. By using these two different strain rate constants in JC equation it is possible to define the strain rate behavior of the material from quasi static to dynamic loading. The two values of the rate sensitivity $C$ were used during numerical simulations to analyze how the value of the strain rate sensitivity can modify the results in terms of force level, residual velocity, ballistic limit and failure process.

It must be noticed that recently the JC constitutive relation, Eq. (6), has been modified by the introduction of non linear terms in approximation of the rate sensitivity [45], to avoid the problem described previously ( 2 sets of constants). This modified form is given by

$\sigma \quad\left[A+B\left(\bar{\varepsilon}^{p}\right)^{n}\right]\left[1+C \ln \dot{\varepsilon}^{*}+C_{2}\left(\ln \dot{\varepsilon}^{*}\right)^{C_{3}}\right]\left[\begin{array}{ll}1 & T^{*} m\end{array}\right]$

where $C_{2}$ and $C_{3}$ are the new material constants allowing to define a non linear strain rates sensitivity. However, this formulation is 


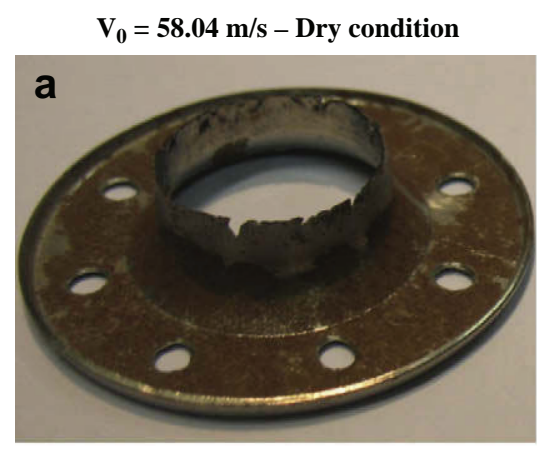

$\mathrm{V}_{0}=72.42 \mathrm{~m} / \mathrm{s}-$ Lubricated condition
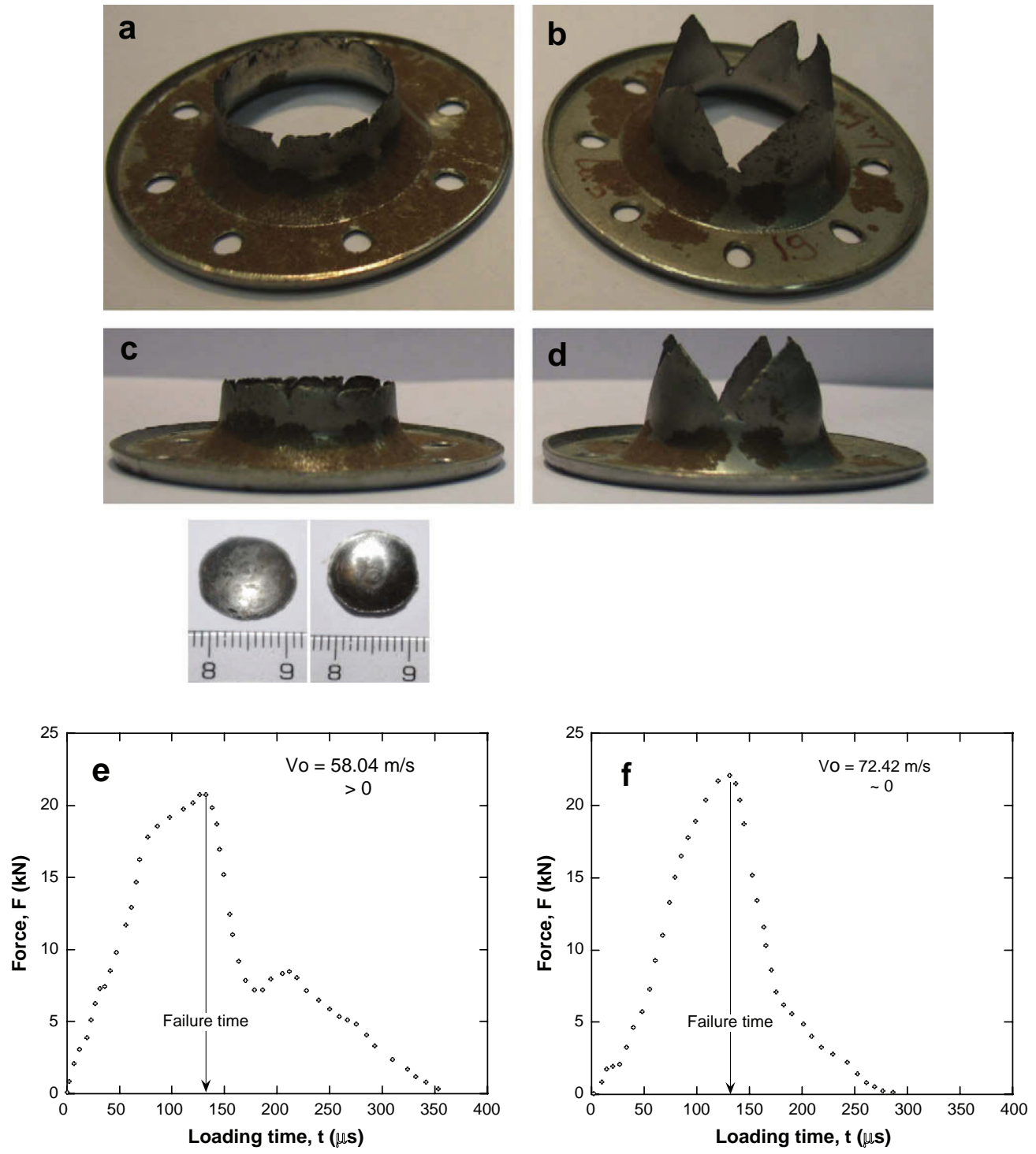

Fig. 4. Failure mode for: (a)-(c) Dry condition with plug ejection definition; (b)-(d) lubricated condition. Corresponding force time history for; (e) dry condition; (f) lubricated condition.

not usually pre implemented in FE commercial codes, including ABAQUS/Explicit.

In order to complete the study a third model has been used during numerical simulations. This approach called RK constitutive relation is based on some physical aspects taking into account thermally activated processes in plasticity which are related to dislocation dynamics, for example Refs. [30,46].

\subsection{Semi physical approach}

The last model, called RK constitutive relation (Rusinek Kle paczko) is described in detail in Ref. [32]. The total stress is decomposed into two parts, Eq. (7)

\section{Table 1}

Chemical composition of the mild steel ES (\% of wt)

\begin{tabular}{lllllllllll}
\hline $\mathrm{Mn}$ & $\mathrm{Al}$ & $\mathrm{Cr}$ & $\mathrm{C}$ & $\mathrm{Ni}$ & $\mathrm{S}$ & $\mathrm{Cu}$ & $\mathrm{Si}$ & $\mathrm{P}$ & $\mathrm{N}$ & $\mathrm{Ti}$ \\
\hline 0.203 & 0.054 & 0.041 & 0.03 & 0.018 & 0.011 & 0.009 & 0.009 & 0.008 & 0.0063 & 0.002 \\
\hline
\end{tabular}

$$
\bar{\sigma}\left(\bar{\varepsilon}^{\mathrm{p}}, \dot{\bar{\varepsilon}}^{\mathrm{p}}, T\right) \quad \frac{E(T)}{E_{0}}\left[\sigma_{\mu}\left(\bar{\varepsilon}^{\mathrm{p}}, \dot{\bar{\varepsilon}}^{\mathrm{p}}, T\right)+\sigma^{*}\left(\dot{\bar{\varepsilon}}^{\mathrm{p}}, T\right)\right]
$$

where $\sigma_{\mu}$ is the internal stress and $\sigma^{*}$ is the effective stress. In this relation Young's modulus $E(T)$ depends on temperature, Eq. (8). The explicit formulation introduced by [47] is given by

$$
E(T) \quad E_{0}\left\{1 \quad \frac{T}{T_{\mathrm{m}}} \exp \left[\theta^{*}\left(\begin{array}{ll}
1 & \frac{T_{\mathrm{m}}}{T}
\end{array}\right)\right]\right\}
$$

where $E_{0}$ is the Young's modulus at zero Kelvin, $T_{\mathrm{m}}$ is the melting temperature and $\theta^{*}$ is a material constant, characteristic of homologous temperature.

The explicit forms of the two stress components are the following, Eqs. (9) and (10),

$$
\sigma_{\mu}\left(\bar{\varepsilon}^{\mathrm{p}}, \dot{\bar{\varepsilon}}^{\mathrm{p}}, T\right) \quad B\left(\dot{\bar{\varepsilon}}^{\mathrm{p}}, T\right)\left(\varepsilon_{0}+\bar{\varepsilon}^{\mathrm{p}}\right)^{n\left(\bar{\varepsilon}^{\mathrm{p}}, T\right)}
$$

$\sigma^{*}\left(\dot{\bar{\varepsilon}}^{\mathrm{p}}, T\right) \quad \sigma_{0}^{*}\left\langle 1 \quad D_{1}\left(\frac{T}{T_{\mathrm{m}}}\right) \log \left(\frac{\dot{\varepsilon}^{\mathrm{max}}}{\dot{\bar{\varepsilon}}^{\mathrm{p}}}\right)\right\rangle^{m^{*}}$ 

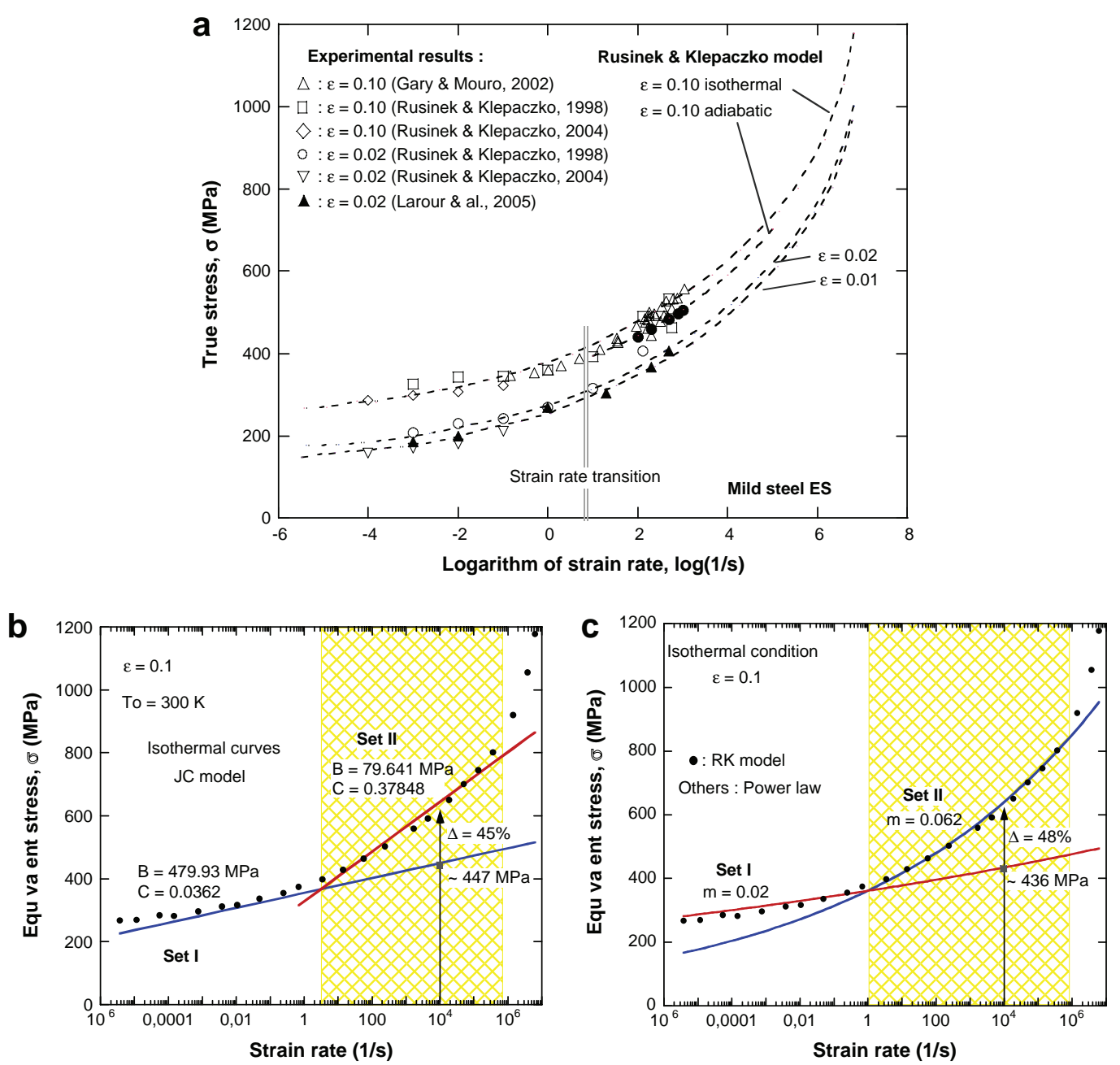

Fig. 5. Strain rate sensitivity of mild steel. (a) Comparison between experimental results and RK equation [36]; (b) comparison between RK and JC equations; (c) comparison between RK and PL equations.

$\varepsilon_{0}$ is the strain level which defines the yield stress at specific strain rate and temperature, $B\left(\dot{\bar{\varepsilon}}^{\mathrm{p}}, T\right)$ is the modulus of plasticity, $n\left(\dot{\bar{\varepsilon}}^{\mathrm{p}}, T\right)$ is the strain hardening exponent of the material, $\sigma_{0}^{*}$ is the effective stress at $T 0 \mathrm{~K}, D_{1}$ is the material constant, $\dot{\varepsilon}^{\max }$ is the upper limit

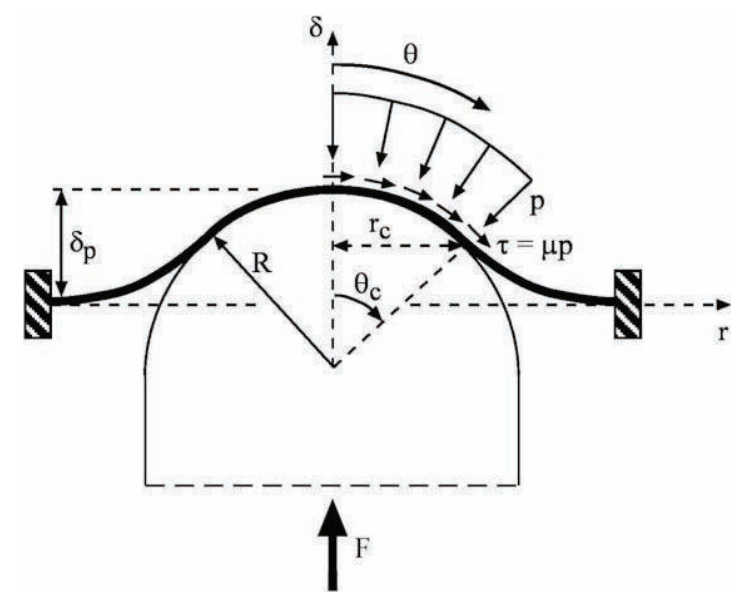

Fig. 6. Equilibrium of the punch tip and definition of the contact angle and radius. of the constitutive relation in terms of strain rate and $m^{*}$ is the constant allowing to define the strain rate temperature depen dency [36].

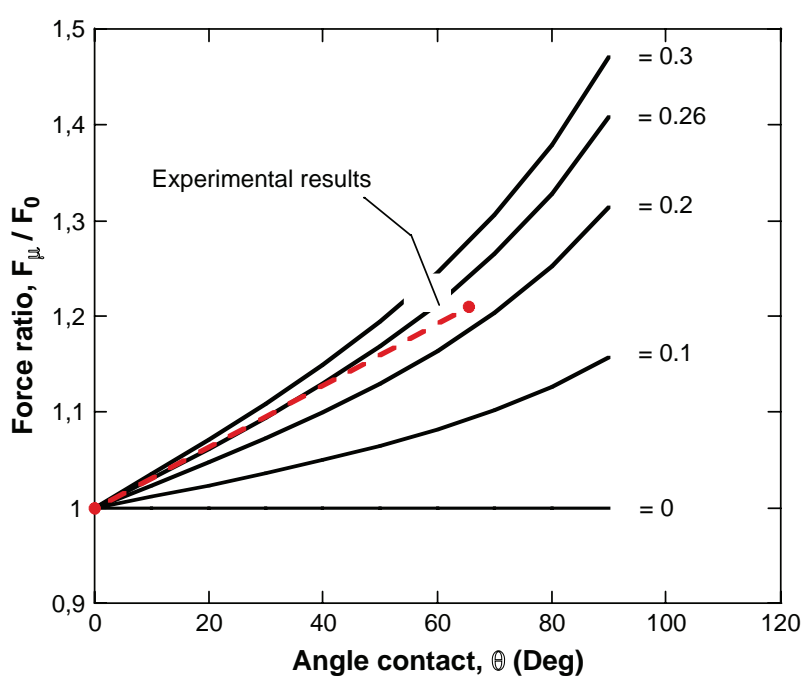

Fig. 7. Calculated values of the force ratio for different coefficient of friction, mild steel ES. 


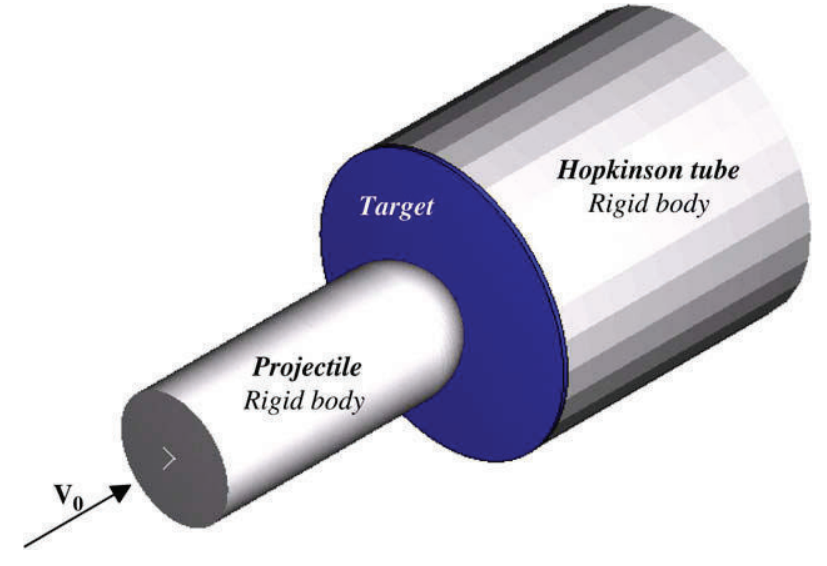

Fig. 8. Configuration applied in the present work.

The modulus of plasticity and the strain hardening exponent are defined by Eqs. (11) and (12):

$B\left(\dot{\bar{\varepsilon}}^{\mathrm{p}}, T\right) \quad B_{0}\left\langle\left(\frac{T}{T_{\mathrm{m}}}\right) \log \left(\frac{\dot{\varepsilon}^{\mathrm{max}}}{\dot{\bar{\varepsilon}}^{\mathrm{p}}}\right)\right\rangle^{-v}$

$n\left(\dot{\bar{\varepsilon}}^{\mathrm{p}}, T\right) \quad n_{0}\left\langle 1 \quad D_{2}\left(\frac{T}{T_{\mathrm{m}}}\right) \log \left(\frac{\dot{\bar{\varepsilon}}^{\mathrm{p}}}{\dot{\varepsilon}^{\mathrm{min}}}\right)\right\rangle$

where $B_{0}$ is the material constant, $v$ is the temperature sensitivity, $n_{0}$ is the strain hardening exponent at $T 0 \mathrm{~K}, D_{2}$ is the material constant and $\dot{\varepsilon}^{\mathrm{min}}$ is the lower limit of the constitutive relation in terms of strain rate $\dot{\varepsilon}_{\min } \approx 10^{-4} \mathrm{~s}^{-1}$. In Fig. 5 it is shown the good correlation of the strain rate sensitivity predicted by RK with the experimental results. The maximum equivalent strain rate reached during the material characterization tests was $\dot{\bar{\varepsilon}} 2800 \mathrm{~s}^{-1}$. Moreover, this level is comparable to the maximum strain rate value obtained in the numerical simulations carried out. Thus, it can be concluded that RK constitutive relation allows for a complete approximation of the strain rate sensitivity of the material during the perforation process, in contrast to the two approaches presented above.

An additional advantage of RK model in order to predict the material behavior when subjected to high temperature and high strain rate is the assumption of strain hardening exponent $n$ taking the general form $n \quad n_{0} f\left(\dot{\bar{\varepsilon}}_{\mathrm{p}}, T\right)$, where $f$ is the weight function. The rate and temperature sensitive strain hardening were introduced into constitutive modelling for the first time in the RK model [37]. This formulation means a clear advantage of RK model in comparison with JC and PL classic formulations in order to repro duce dynamic problems.

When PL, JC, or RK constitutive relations are applied the adia batic increase of temperature during the plastic deformation can be calculated for any process, Eq. (13 a). The adiabatic increase $\Delta T_{\text {adia }}$ of temperature is given by Eq. (13 b)

$T_{\text {adia }} \quad T_{0}+\Delta T_{\text {adia }}$

$\Delta T_{\text {adia }} \quad \frac{\beta}{\rho C_{p}} \int_{\varepsilon^{\mathrm{e}}}^{\bar{\varepsilon}^{\mathrm{p}}} \sigma\left(\xi, \dot{\bar{\varepsilon}}^{p}, T\right) \mathrm{d} \xi$

where $\rho$ is the density of material, $\beta$ is the Taylor Quinney coeffi cient [48] and $C_{p}$ is the specific heat at constant pressure.

For steels, the transition between isothermal and adiabatic conditions appears generally for strain rate of the order, or higher, than $10 \mathrm{~s}^{-1}$ [49]. This transition is caused by a decrease of strain hardening during plastic deformation which is responsible of a thermal softening of the material. The thermal softening triggers very frequently an instability process preceding failure. Fig. 4 shows different modes of instability and failure of sheet metal specimens.

The RK model has already been successfully applied to study several processes of fast deformation such as perforation [32], double shear by direct impact [32], ring fragmentation under radial expansion [9], Taylor test and fast tension test [37,50].

Both, PL and RK constitutive relations have been implemented via a VUMAT in ABAQUS/Explicit using an implicit consistent

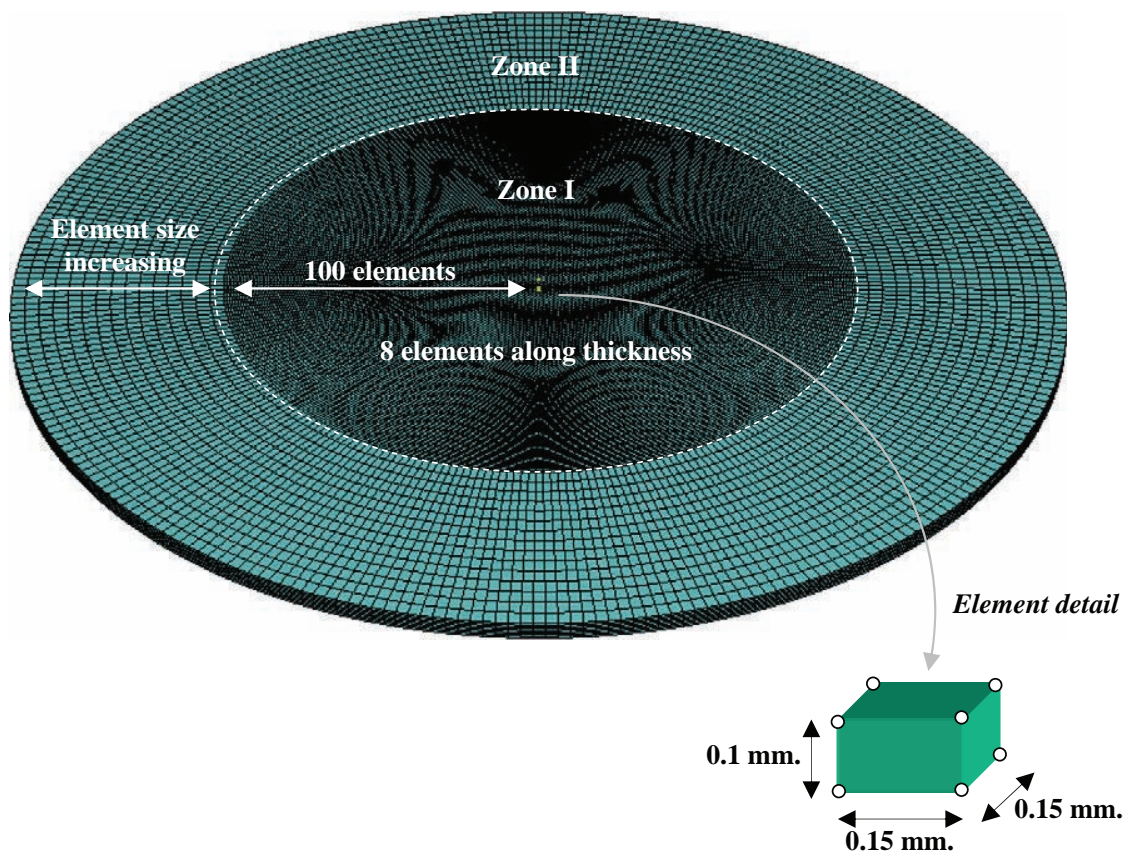

Fig. 9. Mesh configuration used during numerical simulation of perforation. 

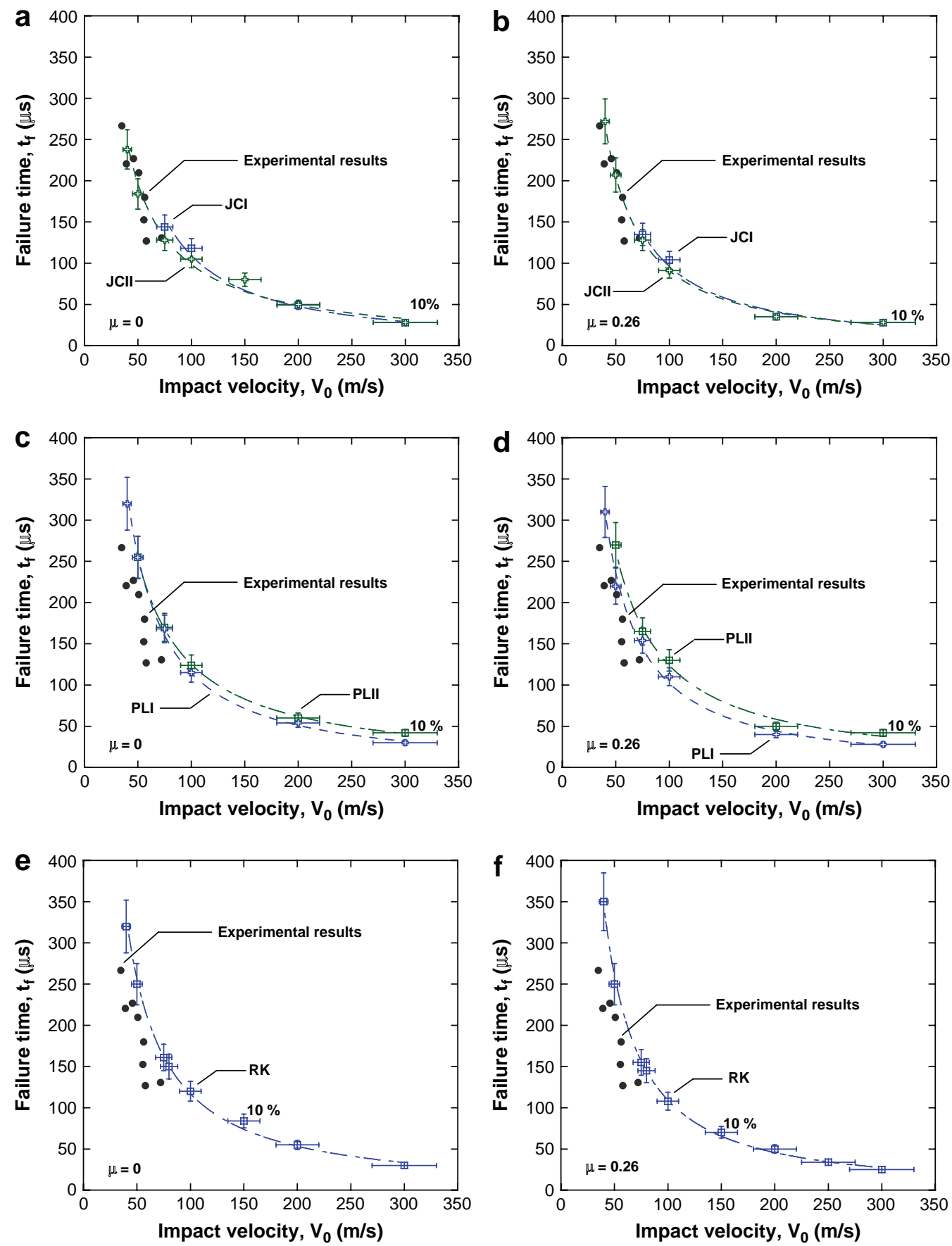

Fig. 10. Numerical estimation of the failure time and comparison with experimental results: JCI and JCII. (a) Lubricated conditions; (b) dry conditions: PLI and PLII; (c) lubricated conditions; (d) dry conditions: RK; (e) lubricated condition; (f) dry conditions.

algorithm developed originally by Ref. [51]. The implementation of the RK model into ABAQUS/Explicit using this algorithm is reported in Ref. [34].

\subsection{Failure criterion}

In order to reproduce the perforation process it is necessary to consider a failure criterion. The use of failure criterions based on an equivalent strain level is widely extended for dynamic applications. In this work a constant value of the equivalent plastic strain at failure was assumed, as it was also adopted by many authors dealing with dynamic problems $[9,52,53]$.
The failure strain value has been defined using several steps. The first one was to estimate the value corresponding to Considère's criterion defined by $\partial \bar{\sigma} / \partial \bar{\varepsilon}_{\mathrm{p}} \quad \bar{\sigma}$ [54]. In order to not disturb the previous solution corresponding to the plastic instability appear ance, a bigger value is taken into account. Thus, the second step was to estimate the strain level corresponding to $\partial \bar{\sigma} / \partial \bar{\varepsilon}_{\mathrm{p}} \quad 0$. The gap between these two values corresponds to the development of the necking process. Finally, a coefficient is applied to this last condi tion as reported by Refs. [55 57] obtaining a final failure strain level of $\varepsilon_{\mathrm{f}}^{\mathrm{p}} \quad$ 1. Moreover, Considère's criterion is used since the failure mode using thin plate is mainly due to necking by tension state followed by crack propagation. Such failure criterion was also 


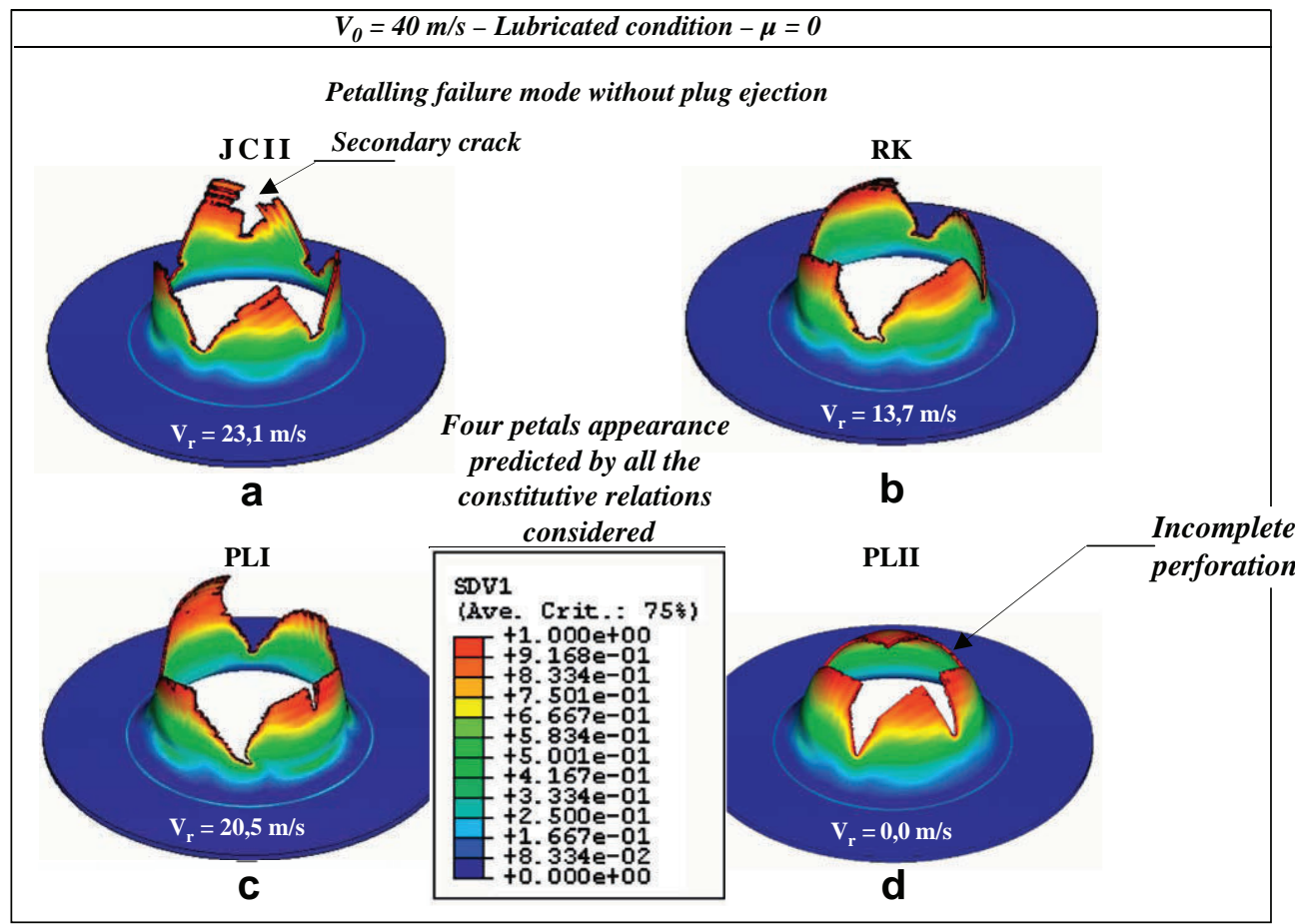

Fig. 11. Equivalent plastic strain contours. Failure mode after impact for different constitutive relations: lubricated condition at $V_{0} \quad 40 \mathrm{~m} / \mathrm{s}$. (a) JCII. (b) RK; (c) PLI; (d) PLII.

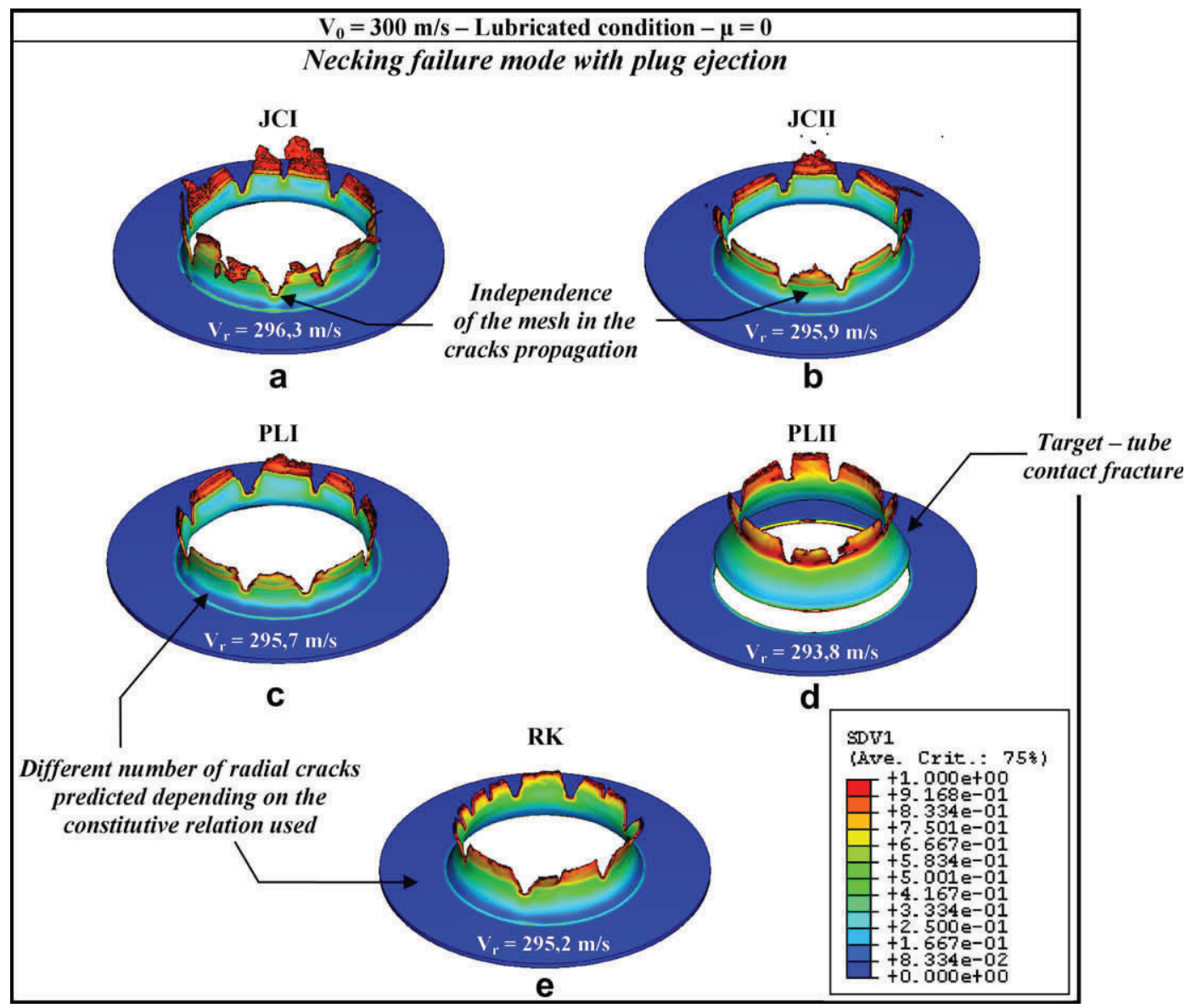

Fig. 12. Equivalent plastic strain contours. Failure mode after impact for different constitutive relations: lubricated condition at $V_{0} \quad 300 \mathrm{~m} / \mathrm{s}$. (a) JCI; (b) JCII; (c) PLI; (d) PLII; (e) RK. 


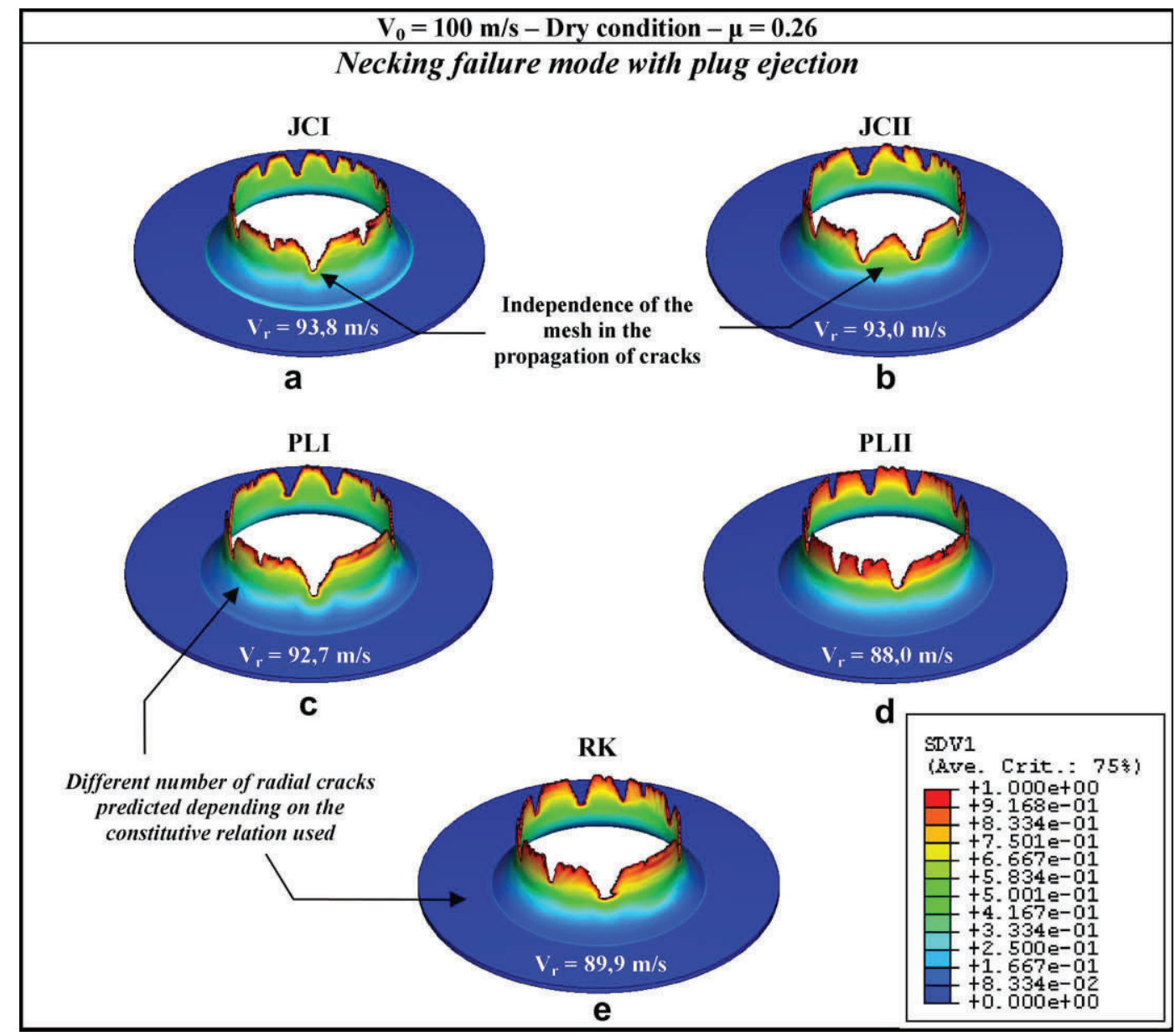

Fig. 13. Equivalent plastic strain contours. Failure mode after impact for different constitutive relations: dry condition at $V_{0} \quad 100 \mathrm{~m} / \mathrm{s}$. (a) JCI; (b) JCII; (c) PLI; (d) PLII; (e) RK.

applied earlier [58 60] for dynamic tension or for ring expansion problems [9,50]. The failure strain is estimated directly from the analysis of deformation in tension predicted by a constitutive relation along with Considère's criterion: $(\mathrm{d} \sigma / \mathrm{d} \varepsilon) \quad \sigma$.

A special attention has been done concerning the energy balance and its preservation during numerical simulations. It must be noticed that the number of elements deleted during the process as consequence of the failure criterion used is vastly reduced (Appendix C). The elimination of elements is restricted to the cracks propagation stage and therefore the energy balance can be considered as preserved.

\subsection{Coefficient of friction analytical approximations combined with experimental data}

The friction can modify the failure mode as it is reported in the next part of this paper. For this reason, the friction coefficient is estimated using punching experiment at low and intermediate velocity. For a given displacement $\delta_{\mathrm{p}}$ of the hemispherical punch, the contact area between the sheet and nose of the punch is limited by a value of the radial coordinate $r_{\mathrm{c}}$, Fig. 6 . Along the contact zone, the sheet is assumed to adopt the spherical nose shape. Experi mental values of $r_{c}$ can be obtained by imposing different displacements to the sheet. Therefore, as $r_{\mathrm{c}}$ depends on the projectile displacement, it also depends on the loading time.

Assuming a constant value of the normal contact pressure $p$ and the friction coefficient $\mu$, the condition of equilibrium of the punch tip allows to obtain the following relation between total force $F$, pressure and coefficient of friction
$F \quad \int_{0}^{\theta_{c}}(p \cos \theta+\mu p \sin \theta) \mathrm{d} S$

where

dS $2 \pi R^{2} \sin \theta \mathrm{d} \theta$

and $\theta_{\mathrm{c}}$ is the contact angle whose value is known through $r_{\mathrm{c}}$ (for a given displacement $\delta_{\mathrm{p}}$ )

$\theta_{\mathrm{c}}\left(\delta_{\mathrm{p}}\right) \quad \sin ^{-1}\left(\frac{r_{\mathrm{c}}\left(\delta_{\mathrm{p}}\right)}{R}\right)$

Integration of Eq. (14) leads to

F $\quad \pi R^{2} p\left[\sin ^{2} \theta_{\mathrm{c}}+\mu\left(\theta_{\mathrm{c}} \quad \sin \theta_{\mathrm{c}} \cos \theta_{\mathrm{c}}\right)\right]$

The ratio $\xi$ between the two forces corresponding to dry $F_{\mu}$ and lubricated $F_{0}$ conditions allows for elimination of the pressure dependency, Eq. (18).

$\xi \quad \frac{F_{\mu}}{F_{0}} \quad \frac{\sin ^{2}\left(\theta_{\mathrm{c}}\right)+\mu\left(\theta_{\mathrm{c}} \quad \sin \left(\theta_{\mathrm{c}}\right) \cos \left(\theta_{\mathrm{c}}\right)\right)}{\sin ^{2}\left(\theta_{\mathrm{c}}\right)}$

With the knowledge of the force ratio $\xi$, Eq. (18), it is possible to define a range for the friction coefficient $\mu$. The obtained force ratios for different values of $\mu$ using Eq. (18) are shown in Fig. 7. Comparing analytical predictions with experimental results, the value of $\mu$ is close to $\mu \quad 0.26$, notably for the contact angle $\theta_{\mathrm{c}} \leq 50^{\circ}$. 

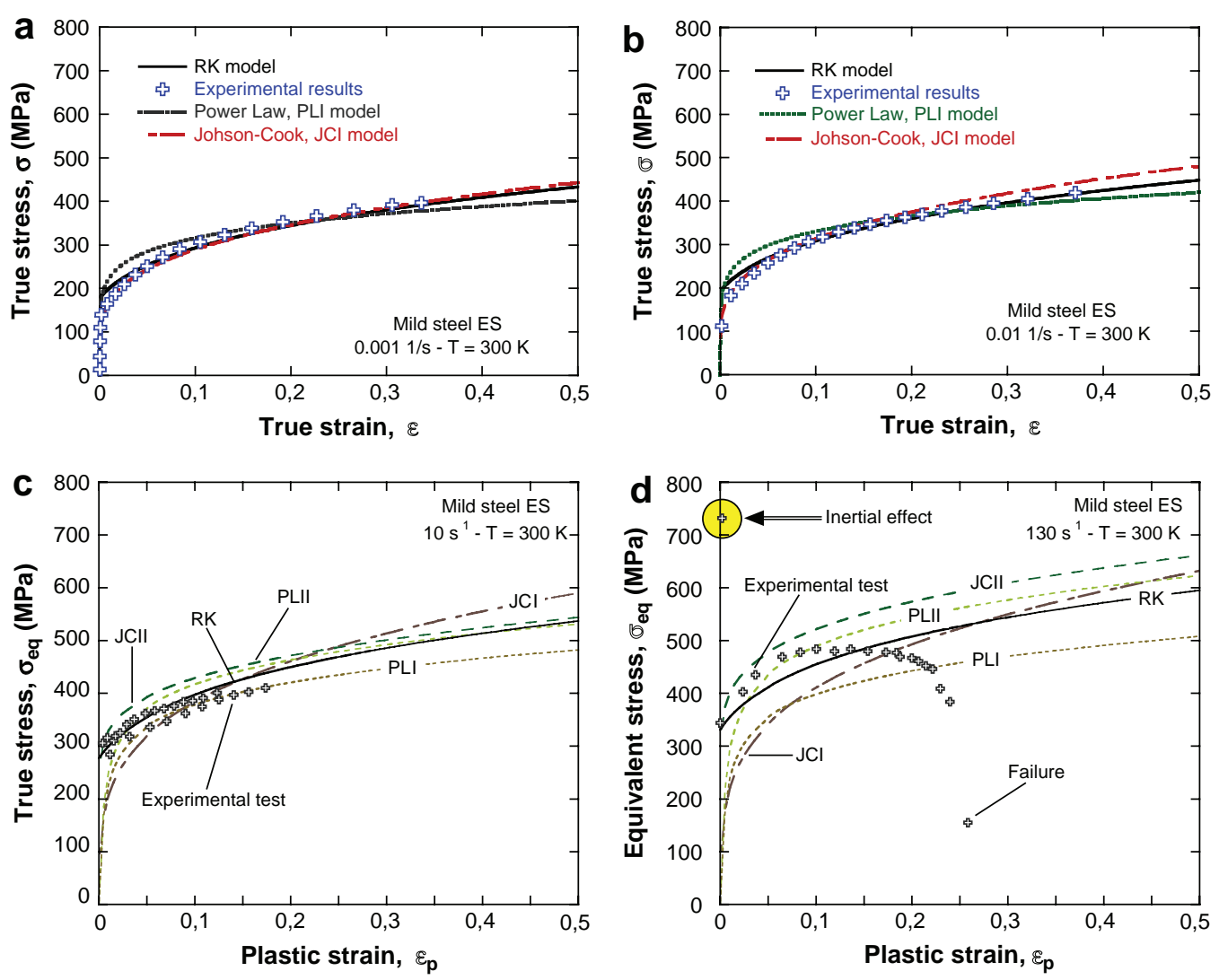

Fig. 14. Comparison of the predictions by different constitutive relations at $T \quad 300 \mathrm{~K}$ and at different initial strain rates. (a) $\varepsilon \quad 0.001 \mathrm{~s}{ }^{1}$; (b) $\varepsilon \quad 0.01 \mathrm{~s}{ }^{1}$; (c) $\varepsilon \quad 10 \mathrm{~s}{ }^{1}$; (d) $\varepsilon 130 \mathrm{~s}^{1}$.

Thus a value of $\mu \quad 0.26$, which corresponds to the upper limit value found (Fig. 7), is used in the numerical simulations to define dry condition. In our case the dependence on the coefficient of friction with temperature and sliding velocity is not taken into account [13,15 17,42,61 63].

\section{Numerical simulation with 3D approach}

This type of impact problems are commonly analyzed numeri cally by means of axi symmetric configuration [13,15 17,64,65].

This simplification permits to obtain results which encourage experimental observations in terms of ballistic limit and residual velocity for different projectile plate experimental configurations $[13,1517,43,60]$. Moreover, the use of this simplification presents an advantage of increasing the mesh density without obtaining excessive computational time. However, a 3D configuration is clearly recommendable when conical, ogival or hemispherical projectiles, susceptible of inducing petalling as the final stage of perforation process, are considered. In order to reproduce numer ically the perforation process induced by this kind of projectiles the

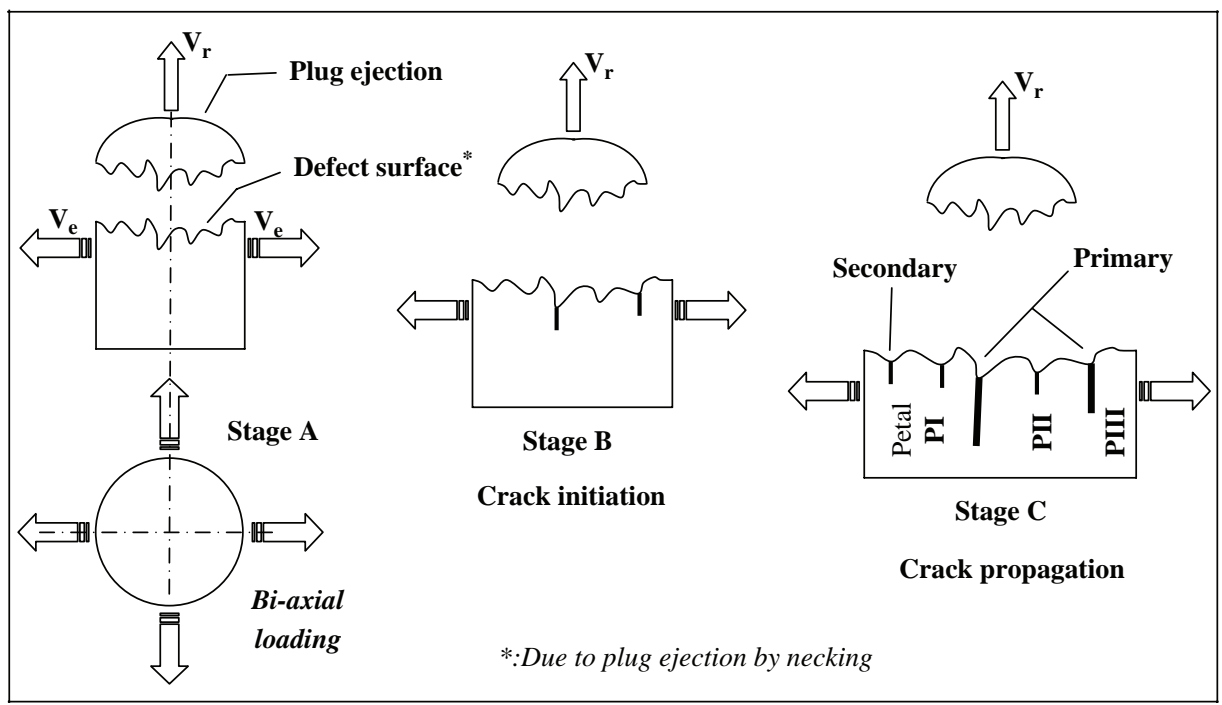

Fig. 15. Schematic representation of petal formation during perforation of sheet steel using lubricated conditions: $V_{\mathrm{e}}$ corresponding to expansion velocity along radial direction and $V_{\mathrm{r}}$ is the residual velocity. 


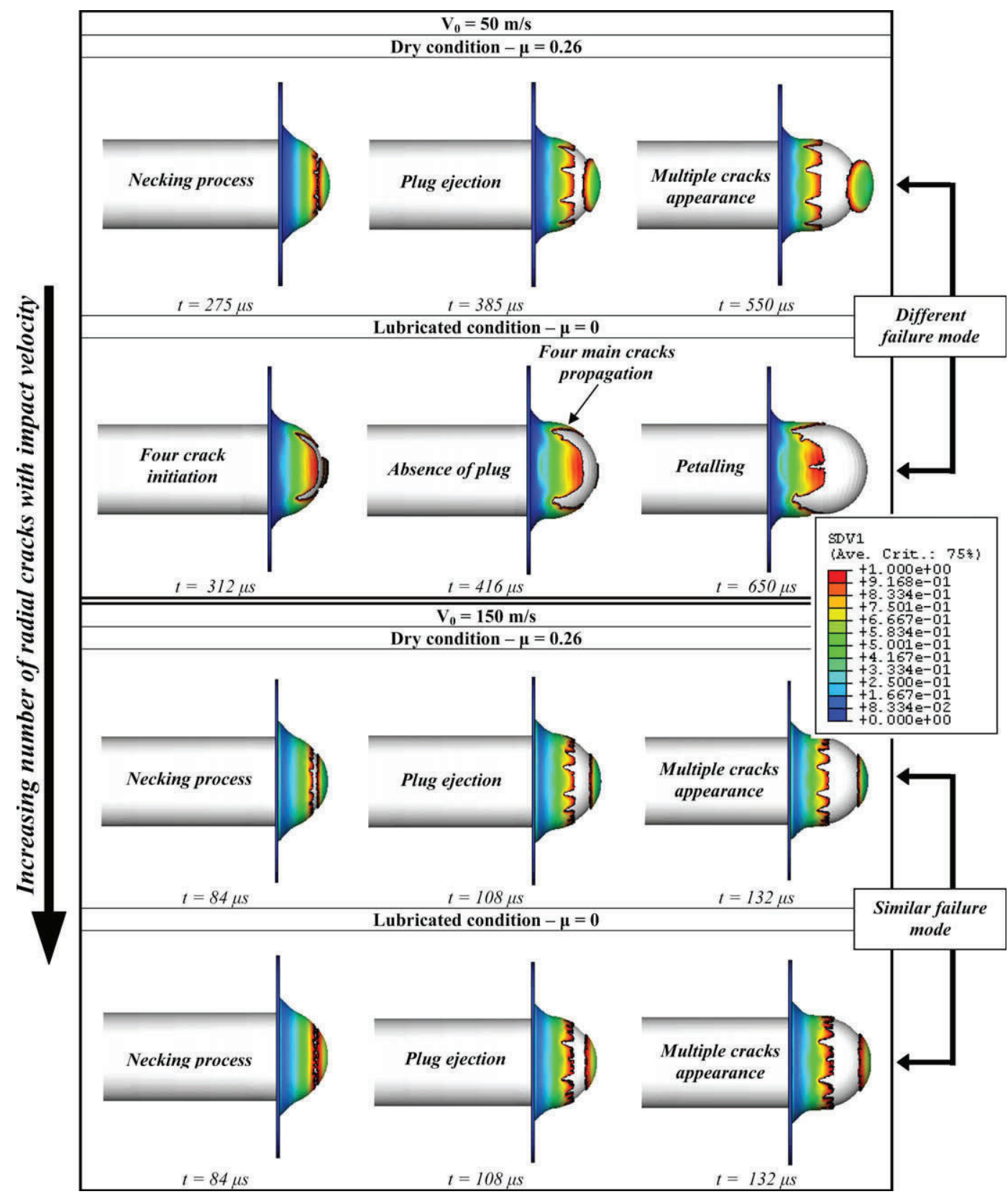

Fig. 16. Equivalent plastic strain contour plots of the perforation process using RK model: $V_{0} \quad 50 \mathrm{~m} / \mathrm{s}(\mathrm{a})$ Dry condition $-\mu \quad 0.26$; (b) lubricated condition - $\mu \quad 0 . V_{0} \quad 150 \mathrm{~m} / \mathrm{s}$ (c) Dry condition $-\mu \quad 0.26$; (d) lubricated condition $-\mu \quad 0$.

element size is not as important as in case of cylindrical projectiles $[13,66]$. Therefore, by performing an adequate mesh configuration the calculation time can be manageable. There is, however, a limited number of works reported in the literature where the perforation process is analyzed by 3D simulations, for example Refs. $[60,61]$.

In the present case, the configuration used in numerical simu lations is showed in Fig. 8.

Both, projectile and Hopkinson tube have been modeled as rigid bodies allowing reduction of the computational time required for simulations. On the other hand, the experimental observations have revealed an absence of erosion on the projectile surface after impact. The reason is that the thin sheet specimen has a low yield stress in comparison with the oil quenched steel of the projectile.

\subsection{Target mesh strategy}

The mesh used in the present paper for the target is shown in Fig. 9. The whole target has been meshed with 8 node tri linear elements with reduced integration (C3D8R in ABAQUS notation [67]) and eight elements along the thickness. The number of elements was 229792 corresponding to 259875 nodes. The elements used to mesh the zone directly affected by impact (Zone I) had a size close to $0.1 \times 0.15 \times 0.15 \mathrm{~mm}^{3}$, Fig. 9. In order to not increase excessively the computational time, the element size has been increased in the zone not affected by the impact, Fig. 9 (Zone II). This optimized mesh has been obtained by a convergence study making use of different mesh densities. The radial symmetry of the mesh avoids spurious generation of main directions for the appearance and progress of cracks. Therefore the position of 

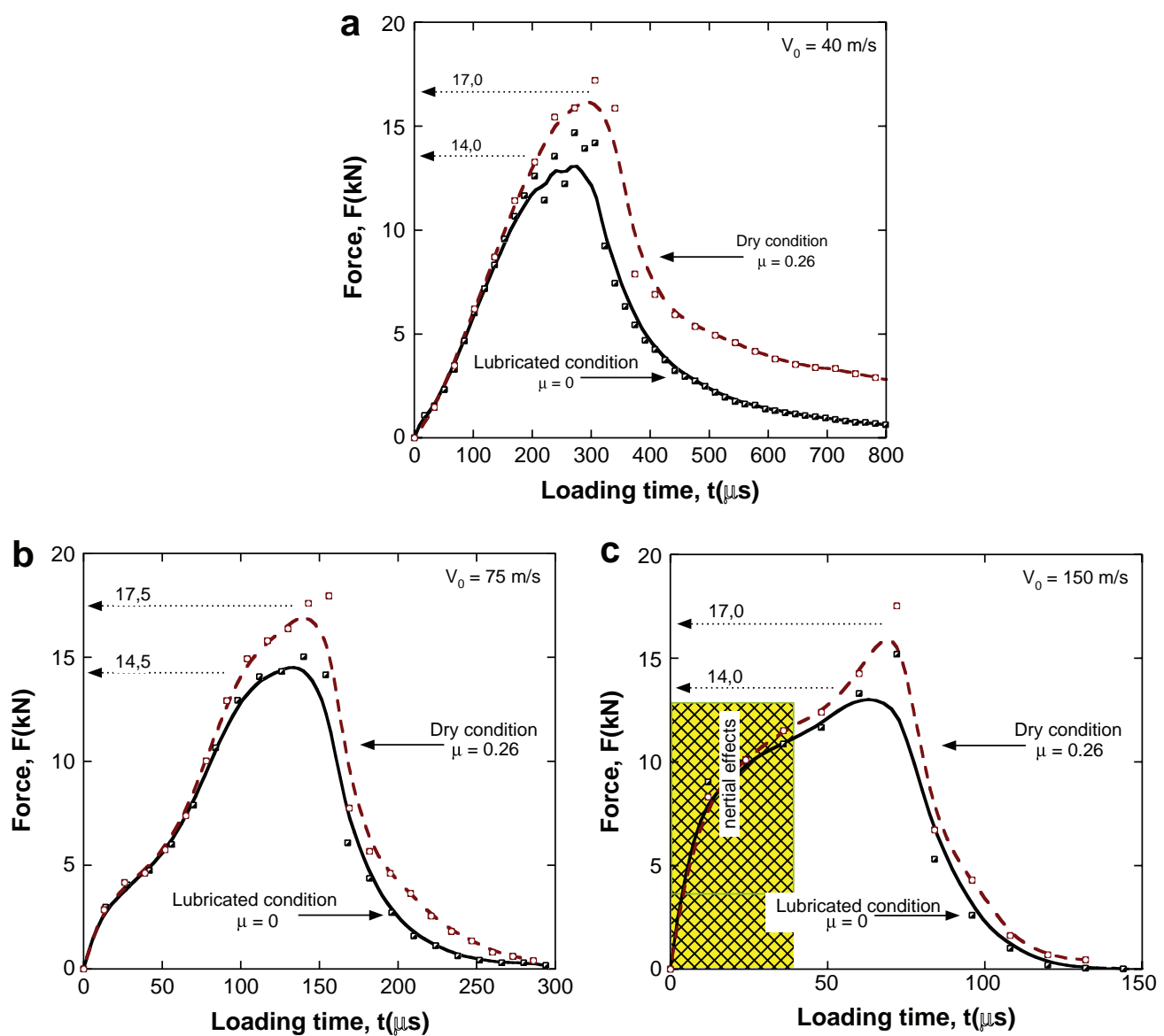

Fig. 17. Force-time history comparison between lubricated and dry conditions for several initial impact velocities using RK model. (a) $V_{0} \quad 40 \mathrm{~m} / \mathrm{s}$; (b) $V_{0} \quad 75 \mathrm{~m} / \mathrm{s}$; (c) $V_{0} \quad 150 \mathrm{~m} / \mathrm{s}$.

the petals at the end of the perforation process just depends on the constitutive relation, impact velocity and friction coefficient applied. This is shown in the next part of the paper.

Using the numerical configuration shown in Figs. 8 and 9 and three constitutive relations already presented, the simulations have been carried out for a wide range of impact velocities varying from $40 \mathrm{~m} / \mathrm{s} \leq V_{0} \leq 300 \mathrm{~m} / \mathrm{s}$.

\section{Analysis and results}

The experimental setup developed in LPMM allows for deter mination of the force time evolution, the displacement time evolution of the projectile during perforation, the time history of the net displacement of the specimen axis and the ballistic limit. At the same time it is possible to compare the target shape after different boundary conditions of impact for both friction and non friction experimental results. This information has been analyzed and used to validate numerical results.

\subsection{Validation and influence of constitutive relations}

The first step is to compare the value of the ballistic limit $V_{\mathrm{bl}}$ predicted by numerical simulations with the value obtained during the experiments. Experiments showed that in the case of dry

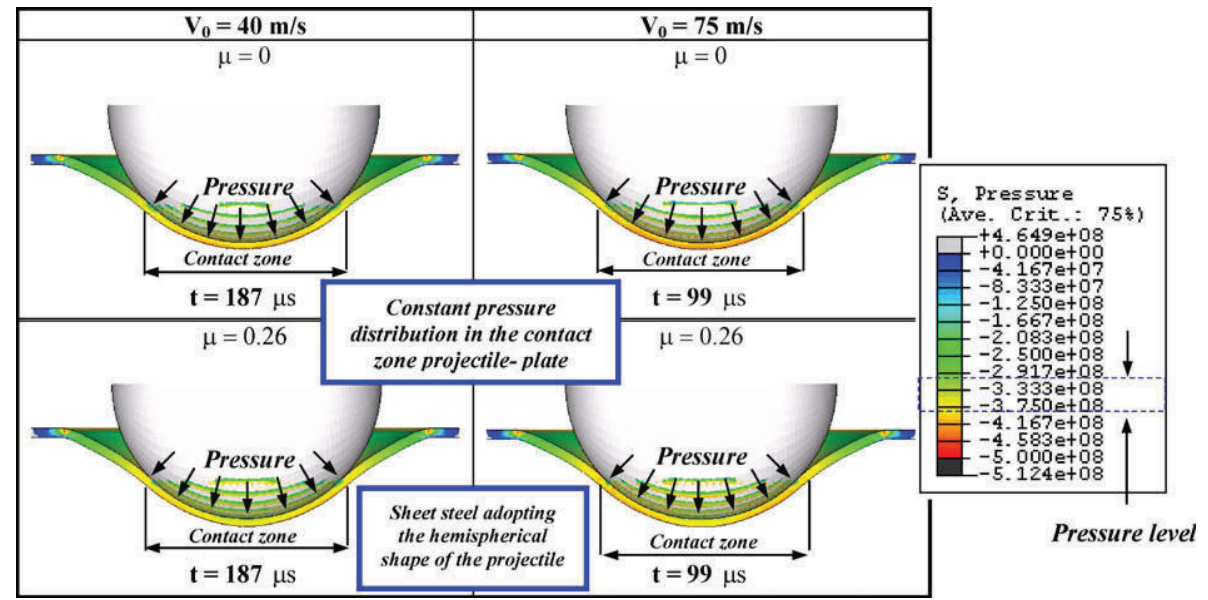

Fig. 18. Pressure distribution during perforation process [Pa]. 


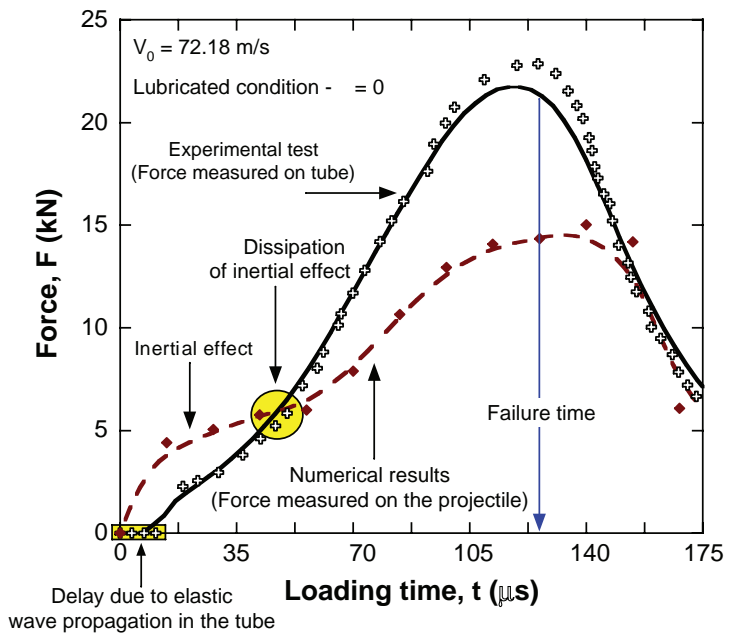

Fig. 19. Comparison of force-time history between experimental measurement via the Hopkinson tube, [37], and numerical estimation via the history of projectile deceleration obtained with RK relation.

conditions the ballistic limit $V_{\mathrm{bl}-\mathrm{dry}} \quad 45 \mathrm{~m} / \mathrm{s}$ is slightly higher that in the case of lubricated contact surface $V_{\mathrm{bl}-l u b} 40 \mathrm{~m} / \mathrm{s}$. The relation between the ballistic limit and the residual velocity of the projectile corresponding to both conditions is well reproduced by the numer ical simulations using all the constitutive relations considered see Appendix B. In addition, the value of the ballistic limit predicted by numerical simulation remains close to the experimental observa tions inside the interval: $0.9 V_{\mathrm{bl}-\exp } \leq V_{\mathrm{bl}-\text { num }} \leq 1.1 V_{\mathrm{bl}-\exp }$ for all cases. It must be noticed, however, that PL and RK are the constitutive relations which predict the closer value of the ballistic limit in comparison with experimental measurements. The results obtained from the simulations with the JC constitutive relation are not so precise. It must be noticed that using JCI the numerical simulations corresponding to impact velocities under $V_{0} \leq 50 \mathrm{~m} / \mathrm{s}$ are prema turely ended due to the appearance of a numerical problem avoiding complete time of calculation. Later, the failure time pre dicted by the numerical simulations is compared with the value obtained during experiments. As reported for the ballistic limit, the numerical values obtained for the failure time are close to the experimental measurements for all the constitutive relations used, except the case of PLII for which the obtained values are out of $10 \%$ range in comparison to the experimental data, Fig. 10. It must be noticed that for numerical simulations corresponding to $V_{0} \geq 100$ $\mathrm{m} / \mathrm{s}$, the numerical estimation of the fracture time cannot be vali dated due to absence of experimental data. The evolution of failure time with the impact velocity for all the constitutive relations used, presents the classical parabolic profile of perforation. This is in agreement with the experimental and numerical data reported in Refs. [13,17,62,64].

Concerning the target shape after impact in the case of lubricated conditions and for impact velocity, $V_{0} \quad 40 \mathrm{~m} / \mathrm{s}$, appearance of four symmetric petals is observed for all constitutive relations, Fig. 11. Although for JCII one can observe a secondary crack that has been arrested before reaching the rear side of the plate, Fig. 11. Anyhow, the failure mode predicted for all cases is petalling with absence of plug ejection. The number and the disposition of the petals are in agreement with the experimental observations, Fig. 4b. Albeit, some differences in the residual velocity can be observed, Fig. 11.

On the contrary to the failure mode for $V_{0} \quad 40 \mathrm{~m} / \mathrm{s}$, in the case of $V_{0} \quad 300 \mathrm{~m} / \mathrm{s}$ and lubricated conditions the number of simulated radial cracks changed substantially depending on the constitutive relation, Fig. 12. Notice that the higher number of radial cracks corresponds to the case with the higher residual velocity, JCI, Fig. 12. The relevance of this agreement will be analyzed ahead in this paper. In addition, using PLII model the failure of the plate is produced in the zone corresponding to the contact: plate Hop kinson tube. Anyhow, the failure mode predicted is common to all constitutive relations. That is ejection of a plug as the final stage of the perforation process.

It is shown in Fig. 13, for the case of dry conditions and $V_{0} \quad 100 \mathrm{~m} / \mathrm{s}$, that for all constitutive relations the failure mode is in agreement with the experimental observations, Fig. 4a c. That is, a plug ejection as the final stage of perforation and therefore reduction of petalling. Nevertheless, the number of radial cracks changes with the constitutive relation applied. Again, the number of radial cracks predicted numerically is larger when the residual velocity is higher, JCI, Fig. 13.

Fig. 14 shows stress vs. strain curves predicted by each constitu tive relation and the comparison with experimental data for mild steel ES. These curves reproduce the true stress vs. true plastic strain relations defined by Eqs. (3), (4) and (7) for $T 300 \mathrm{~K}$ and different strain rates $\dot{\varepsilon} 0.001 \mathrm{~s}^{-1}, \dot{\varepsilon} \quad 0.01 \mathrm{~s}^{-1}, \quad \dot{\varepsilon} \quad 10 \mathrm{~s}^{-1}$ and $\dot{\varepsilon} 130 \mathrm{~s}^{-1}$. Also a comparison with experimental curves is repor ted. In the case of low strain rates JCI, PLI and RK fit correctly the experimental results, Fig. 14a b, however, JCII and PLII are not able to define the behavior at low strain rate since they are fitted for strain rates larger than $10 \mathrm{~s}^{-1}$, Fig. 14c d. For this reason at high strain rates JCII and PLII produce better results with experiments. However, it is observed that RK constitutive relation is able to reproduce the material behavior in the whole spectrum of strain rates as shown in Fig. 14. These differences in the predicted material behavior modify considerably the response of plate during perforation. The different behavior predicted by each constitutive relation will affect the absorption of energy consumed in the process of perforation. It is therefore possible to introduce some modifications in the failure mode of the target, the main goal of analysis in the present work.

In order to demonstrate the importance of defining correctly the material behavior, and particularly the effect of underestimating the flow stress, an extreme case has been taken into account. This extreme case consists of subtracting the term corresponding to the strain rate sensitivity from the JC formulation. The main goal is to investigate the relevance of the strain rate on the perforation process and at the same time the effect of the decrease of the flow stress of the target material.

As result of this analysis see Appendix D it is observed how a decrease of the rate sensitivity of the flow stress induces a reduction of the plastic field during perforation. In that case the inertia effects become relevant and it favours the appearance of a greater number of radial cracks. This explains the previously reported relation between the number of radial cracks and residual velocity. As it is analyzed in the next part, this effect is equivalent to an increase in the impact velocity.

In view of the complexity of the processes of dynamic failure and the strong influence of the material behaviour, it is necessary to use a precise constitutive relation. Such equation should permit to predict the response of the material with a good precision within a wide range of load conditions. Therefore relying on the good results that RK constitutive relation has offered for the problem treated in the present work as well as for other problems that involve the appearance of plastic instabilities [9,50], this constitu tive relation was chosen to perform a more complex analysis of the perforation depending on the impact velocity and the conditions of friction. Simulations performed under those assumptions are reported in the following part of the paper.

\section{Analysis of the perforation process}

In addition to the numerical simulations dealing with the role of the constitutive relation in analyzing the target behavior in the perforation process, in the next part of the paper a detailed analysis 


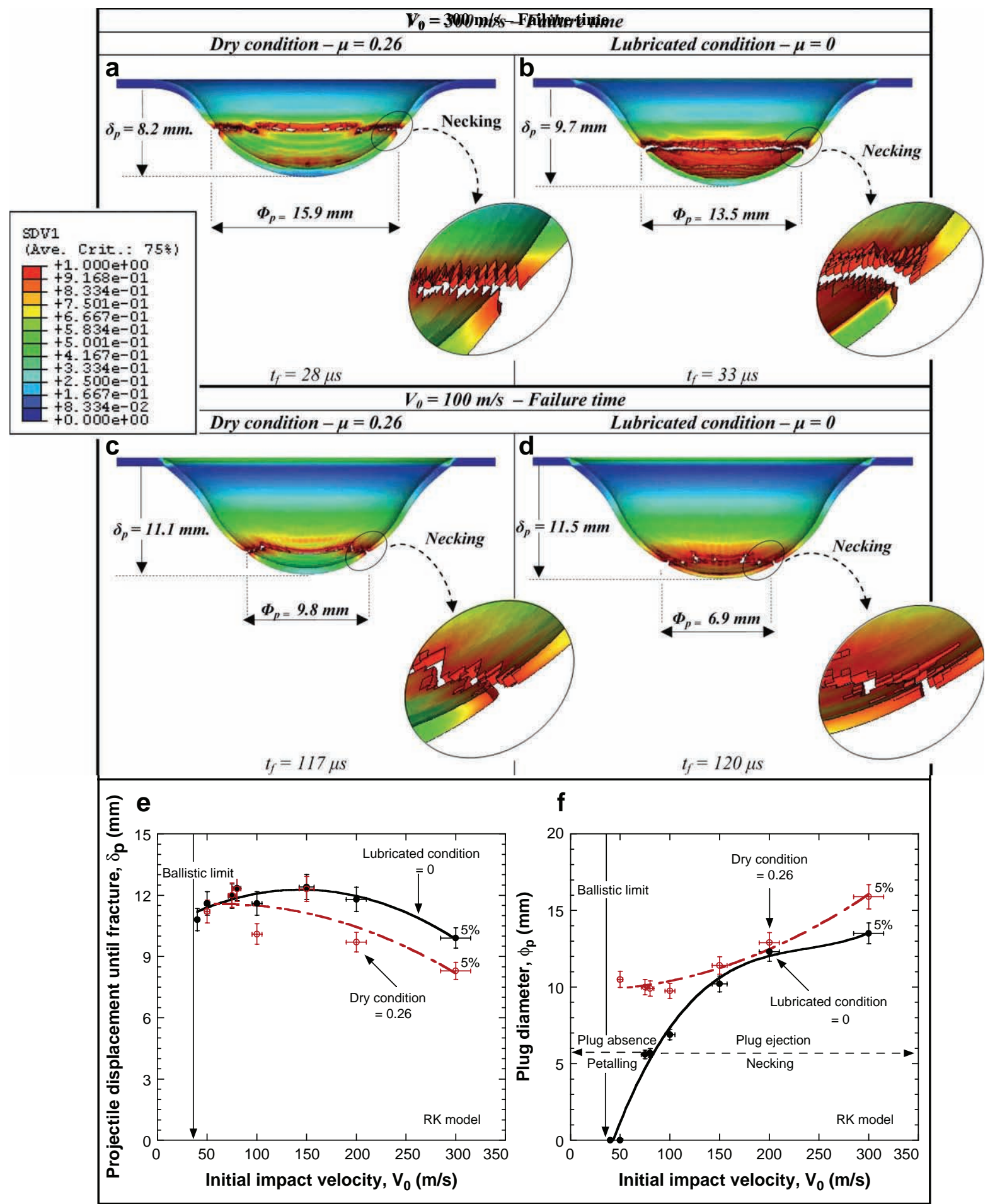

Fig. 20. Equivalent plastic strain contours at instant of failure for dry and lubricated conditions $-(\mathrm{a}, \mathrm{b})-V_{0} \quad 300 \mathrm{~m} / \mathrm{s}$; (c), (d) $V_{0} \quad 100 \mathrm{~m} / \mathrm{s}$; (e) numerical estimation of projectile displacement until fracture and (f) plug diameter using RK constitutive relation for lubricated and dry conditions.

is offered showing the effects of impact velocity and friction on the failure mode. In this part of the numerical study only RK consti tutive relation was applied.

\subsection{Effect of friction}

In the present case, different kinds of failure mode are found during impact of steel sheets depending mainly on the friction coefficient $\mu$ and on the impact velocity. Thus, for dry contact
( $\mu \approx 0.26$ ) the top of the projectile is stuck to the steel sheet inducing a circumferential failure by necking. The diameter of the circumferential failure is close to projectile diameter. It follows by initiation of small radial cracks, Fig. 4a, c. The process of failure observed for lubricated case is slightly different. For the last case $(\mu \approx 0)$, due to radial sliding of the steel sheet along the projectile nose a small plug ejection appears close to the dome of the sheet steel, stage A, Figs. 4a c and 15. In that case the process of hole enlargement is longer allowing to initiate more small cracks, stage 


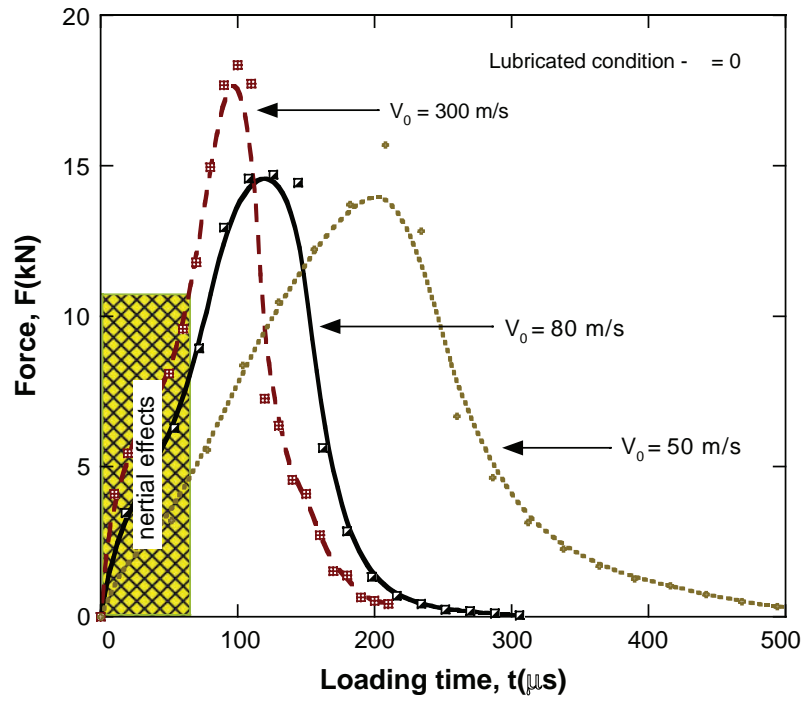

Fig. 21. Force-time history for lubricated conditions and several initial impact velocities using RK constitutive relation.

B, responsible of petal formation as ultimate stage by crack prop agation, stage $\mathbf{C}$.

Both situations are faithfully reproduced during numerical simulations in agreement with the experimental observations (Fig. 4) using the RK constitutive relation, Fig. 16. For dry condition ( $\left.\begin{array}{ll}\mu & 0.26\end{array}\right)$ ejection of a plug is observed as the final stage of perforation process for the whole range of impact velocities considered.

Nevertheless, in the case of lubricated conditions ( $\left.\begin{array}{ll}\mu & 0\end{array}\right)$, the plug ejection appears only when the ballistic limit is considerably exceeded, that is for $V_{0} \geq 100 \mathrm{~m} / \mathrm{s}$, Fig. $16 \mathrm{~d}$. This effect has been observed and studied previously in tension and perforation. Such effect is due to the trapping of plastic deformation, leading to the Critical Impact Velocity effect, as reported in Refs. [68,69]. When that impact velocity is reached, the hole enlargement process becomes reduced and the target failure is induced by circumferential necking, it causes a plug ejection. Thus, for a high

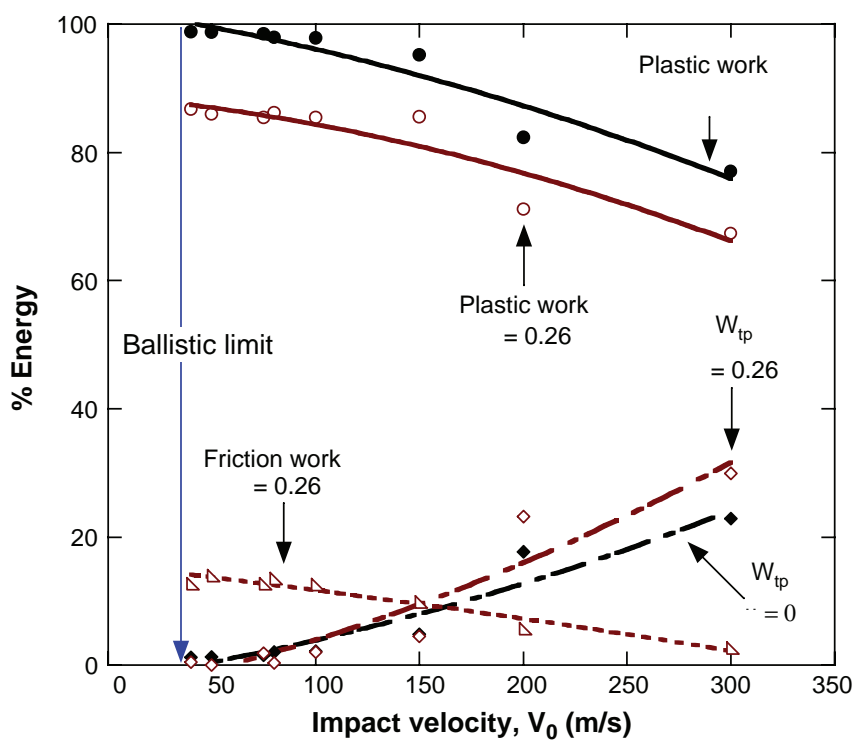

Fig. 22. Energy balance of the perforation process analyzed via RK constitutive relation. impact velocity, the differences concerning the failure mode between dry and lubricated condition become reduced.

Anyway, the friction effect is observed in the whole considered range of impact velocity by measuring the force time history. The force level is slightly larger in case of dry condition, $\mu \quad 0.26$, due to the friction effect. The difference in the maximum force level between the numerical values obtained for $\mu \quad 0.26$ and $\mu \quad 0$ seems to remain independent of the impact velocity, Fig. 17.

This fact is in agreement with the experimental observations and also with the hypothesis assumed to obtain the analytical prediction of the friction coefficient used for dry conditions, $\mu \quad 0.26$. Moreover, the constant value used for the friction coeffi cient based on the assumption of a constant pressure along the contact zone projectile plate is supported by the results obtained from the numerical simulations as reported in Fig. 18.

It is observed using this measurement technique (force obtained by the knowledge of projectile deceleration history) that inertia effect appears at the beginning of loading, Fig. 19. When the inertia effect is dissipated, a quasi static loading curve is obtained, as for example when the force is measured along the Hopkinson tube, as reported in Ref. [37]. However, even if the force history is different, the energies absorbed by the target are very close. A complete analysis is reported in Ref. [37] concerning the effect of point measurement during experiment. In the present case, as the tube is defined as rigid, the force is obtained via time deceleration of the projectile.

Moreover, the friction level can also be observed for any impact velocity by measuring the plug size. This is possible since the tangential stress that appears by the friction amplifies the process of necking and therefore favours plug ejection. In the case of $\mu \quad 0.26$ the plug diameter is always larger than in the case of $\mu \quad 0$. The largest difference appears for impact velocities close to the ballistic limit. In that case for $\mu \quad 0$ and $V_{0} \leq 70 \mathrm{~m} / \mathrm{s}$ there is no plug ejection, Fig. 20.

Another possibility to quantify the friction effect, which is directly related with the plug size, is the displacement of projectile at failure time. The results obtained from the numerical simulations reveal that this parameter is larger when $\mu \quad 0$. This statement is true for the complete range of impact velocities considered, Fig. 20. The displacement of the projectile at failure quantifies the larger deformation of the target in the case of $\mu \quad 0$.

\subsection{Influence of impact velocity}

Influence of impact velocity, $V_{0}$, on the failure mode considering both conditions of friction, $\mu \quad 0$ and $\mu 0.26$, can be easily observed. In both friction conditions, the number of radial cracks increases with impact velocity. This phenomenon is induced by the increase of the circumferential strain level responsible of the crack initiation and progression [21]. This is caused by the increase of the kinetic energy transferred to the material of the target when the impact velocity increases. Although the number of cracks is larger in case of high impact velocity, the failure mode induced by necking that appears in this situation reduces the size of the petals.

In addition, the initial impact velocity affects also the force level during perforation. The maximum force is reached at the maximum impact velocity considered, $V_{0} 300 \mathrm{~m} / \mathrm{s}$, and next it decreases with impact velocity, Fig. 21 . This effect is caused by the strain rate sensitivity of the material target. At high impact velocity the mean strain rate increases and the target material is subjected to a strong process of strain hardening, which in turn increases the mean force. This process is limited at low impact velocity where the force level is reduced.

In order to analyze the phenomena involved in the process, an energy balance is proposed, defined by Eq. (19). 


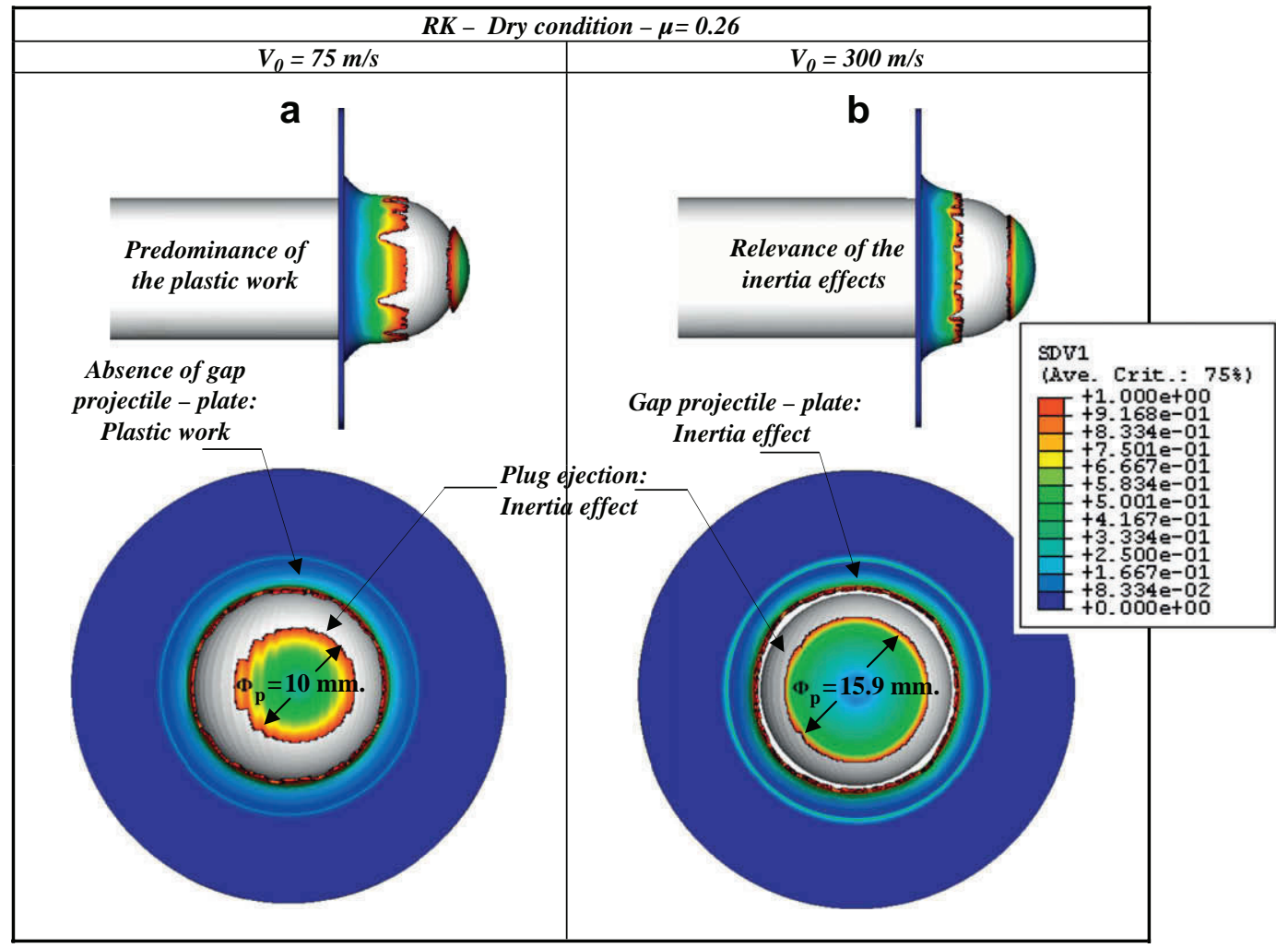

Fig. 23. Equivalent plastic strain contours. Gap between projectile-plate predicted via RK constitutive relation, dry condition. (a) $V_{0} \quad 75 \mathrm{~m} / \mathrm{s}$; (b) $V_{0} \quad 300 \mathrm{~m} / \mathrm{s}$.

$\Delta K_{\mathrm{p}} \quad W_{\mathrm{p}}+W_{\mathrm{f}}+W_{\mathrm{tp}}$

where $\Delta K_{\mathrm{p}}$ is the kinetic energy lost by the projectile, $W_{\mathrm{p}}$ is the plastic work, $W_{\mathrm{f}}$ is the friction energy and $W_{\mathrm{tp}}$ is the kinetic energy transferred into the plate. Globally, it can be observed how at low impact velocity the process is governed by the plastic work, however, when the impact velocity increases the inertia effects become predominant due to larger amount of kinetic energy transferred into the plate, concentrated mainly in the kinetic energy of the plug, Fig. 22.

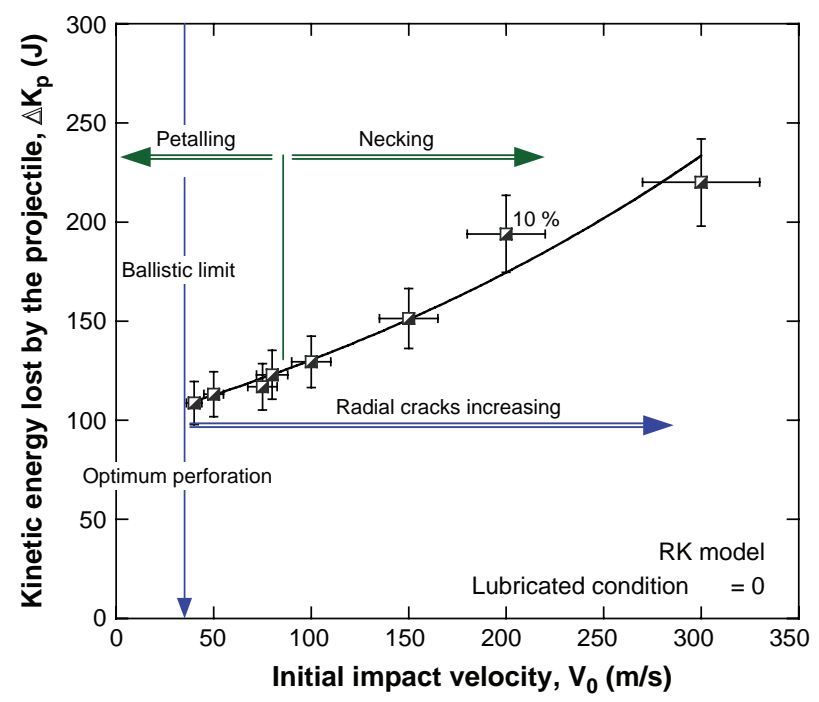

Fig. 24. Kinetic energy $\Delta K_{\mathrm{p}}(\mathrm{J})$ lost by the projectile as predicted by the application of RK constitutive relation and ideal lubrication, $\mu \quad 0$.
However, some differences appear between lubricated and dry conditions. In the case of $\mu \quad 0$, and the impact velocity close to the ballistic limit, the plastic work represents almost $100 \%$ of the energy absorbed by the plate. This quantity is reduced in the case of $\mu \quad 0.26$ by contribution to the work of friction. For initial impact velocity $V_{0} \geq 150 \mathrm{~m} / \mathrm{s}$ the contribution of inertia effects is clearly higher in the case of $\mu \quad 0.26$. As previously discussed, the plug size is larger for dry conditions.

In addition, the increase of the inertia effect with impact velocity can be measured by the gap projectile plate which appears when a certain impact velocity is exceeded, $V_{0} \geq 150 \mathrm{~m} / \mathrm{s}$, Fig. 23. This generates a hole expansion process [70].

It is observed after Fig. 22 how a complete petalling (lubricated condition for $V_{\mathrm{bl}} \leq V_{0} \leq 100 \mathrm{~m} / \mathrm{s}$ ) is restricted in perforation processes completely governed by plastic work. In that case, an absence of plug ejection is found.

\subsection{Analysis of petalling process}

In order to study the petalling process, several studies based on analytical developments can be found in the international litera ture explaining the mechanics responsible for such behavior. Traditionally, the petalling process in the analytical models avail able in the literature is approximated as a simple hole enlargement [71 74]. However, the theories proposed in Refs. [75] and [21] have approached the process by means of a more rigorous treatment.

In Ref. [21] it is reported that the appearance of four or five symmetric petals corresponds to a minimum for total rate of energy dissipation. The experiments performed in the present work for lubricated condition also satisfied the previous observations. At impact velocity close to the ballistic limit the number of petals appearing is four. In this situation the energy needed by the projectile to perforate the plate is minimum, Fig. 24. 


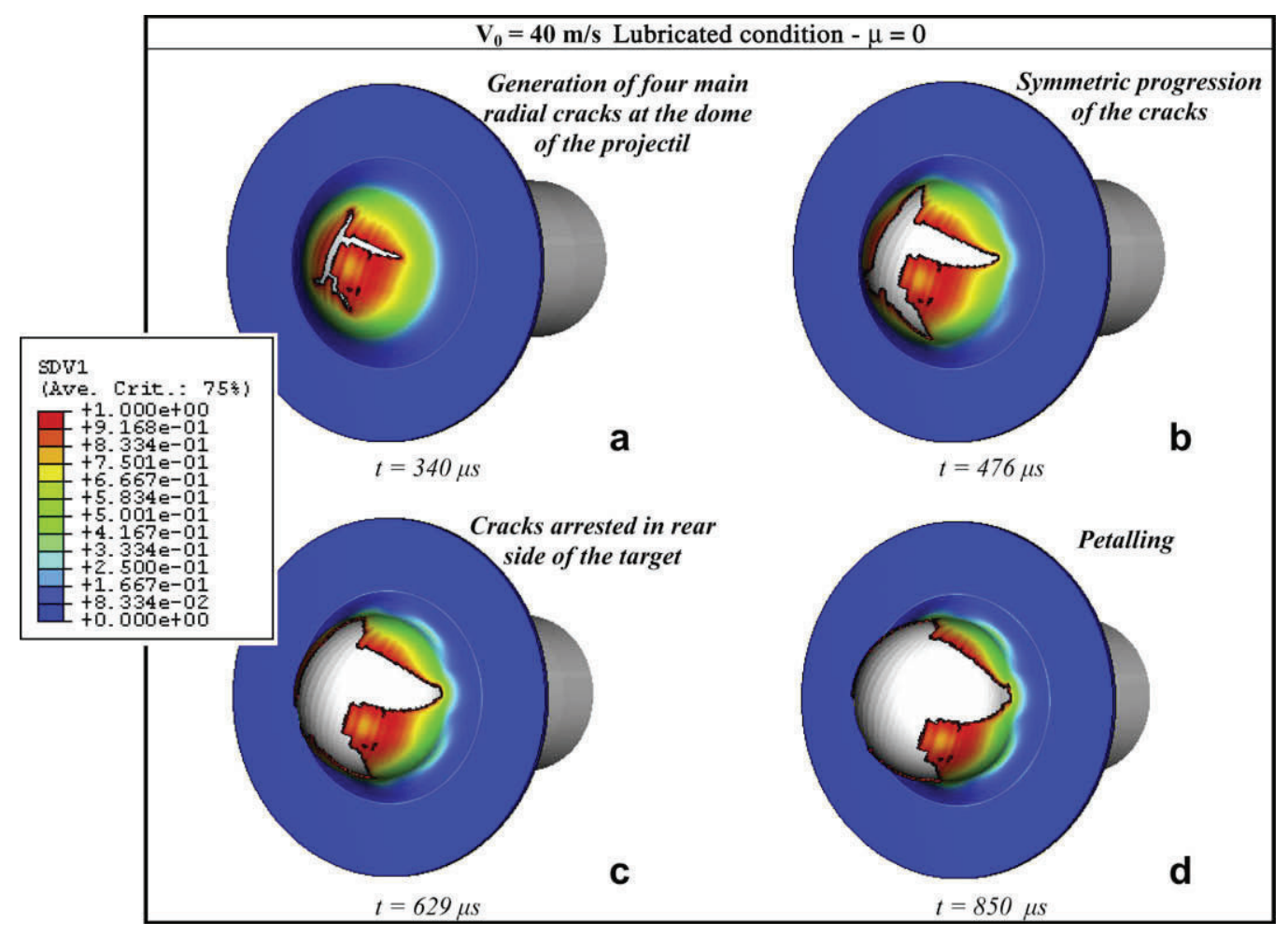

Fig. 25. Equivalent plastic strain contours during petalling process using RK constitutive relation. $V_{0} \quad 40 \mathrm{~m} / \mathrm{s}$; lubricated condition $-\mu \quad 0$.

This fact is well defined by the numerical simulations performed with application of RK constitutive relation, Fig. 24. In such case the damage induced by the projectile in the sheet steel is concentrated in the dome of the target by avoiding necking and therefore plug ejection, Fig. 25. This induces generation of several cracks in the zone, four of them quickly progress inducing the formation of four petals symmetrically disposed, Fig. 25. The fast progression of the cracks triggers an increase of the circumferential strain induced by the projectile advances.

The circumferential plastic strain in adiabatic conditions strongly increases the temperature at the bottom of the crack. This induces a local thermal softening, commonly responsible of insta bilities' appearance in dynamic problems [9,50,68,69,76 80], which favours the fast progression of the cracks and diminishing the amount of energy absorbed by the plate during the perforation.

Three different stages of the perforation process have been analyzed in order to quantify the local gradient of temperature in the proximity of the cracks, Fig. 26. The first stage (Stage I) corre sponds to the early development and progression of cracks, the second one (Stage II) represents the progression of cracks and the third one (Stage III) leads to the crack arrest. It is observed that the temperature quickly decreases as one moves away from the crack. The temperature distribution is represented by the parabolic profile, Fig. 26.

Thus, Fig. 26 shows a gradient of temperature in the zone close to the crack: $x \leq 1 \mathrm{~mm}$ ( $\mathbf{x}$ distance from the crack), for stage II and stage III, being slightly minor in case of stage $\mathbf{I}$. The reason of this difference is that for stage I the zone beside the crack is not fully plastic and an external contribution of energy represented by the force induced by the advance of the projectile is needed to propagate the crack. However, in the case of stage II the strong temperature gradient coupled with the high level of circumferen tial strain caused by the advances of the projectile induces the progression of the crack with just a small amount of energy absorbed by the plate. In the case of stage III, although the gradient of temperature is comparable to stage II, the circumferential strain is not large enough to induce the crack progression and cracks are finally arrested close to the rear side of the target.

In the case of $x \geq 1 \mathrm{~mm}$, the temperature decay is progressive until reaching $T \approx 293 \mathrm{~K}$ which corresponds to a zone with absence of plastic deformation. The relevance of the gradient of tempera ture during the crack progression demonstrates that the constitu tive model used to define the behavior of the plate in perforation problems, susceptible of inducing plastic instabilities such as pet alling, is crucial.

\section{Conclusions}

The failure process of steel sheets when subjected to normal impact by hemispherical projectiles was examined. Experiments have been carried out using an original setup developed in LPMM of Metz University based on the R.M. Davies bar concept by the application of Hopkinson tube. The tests were conducted covering a wide range of initial impact velocities. Lubricated and dry conditions were applied between specimen and steel sheet making possible the analysis concerning the influence of friction during perforation process. Numerical calculations have been made by the application of 3D analysis using ABAQUS/Explicit FE code and considering three different constitutive relations, JC, PL and RK. The last constitutive equation allows for a complete approximation of the non linear strain rate sensitivity. However, in the cases of JC and PL constitutive equations the strain rate sensitivity must be approximated in several parts. Therefore, RK relation is chosen to carry out the numerical analysis of the perforation process. Since it is well known that impact events are strongly coupled with strain hardening, strain rate sensitivity and adiabatic temperature increase, a precise approximation of mate rial behavior is crucial.

In addition, the friction effect on the failure mode has been analyzed. Close to the ballistic limit velocity, appreciable 


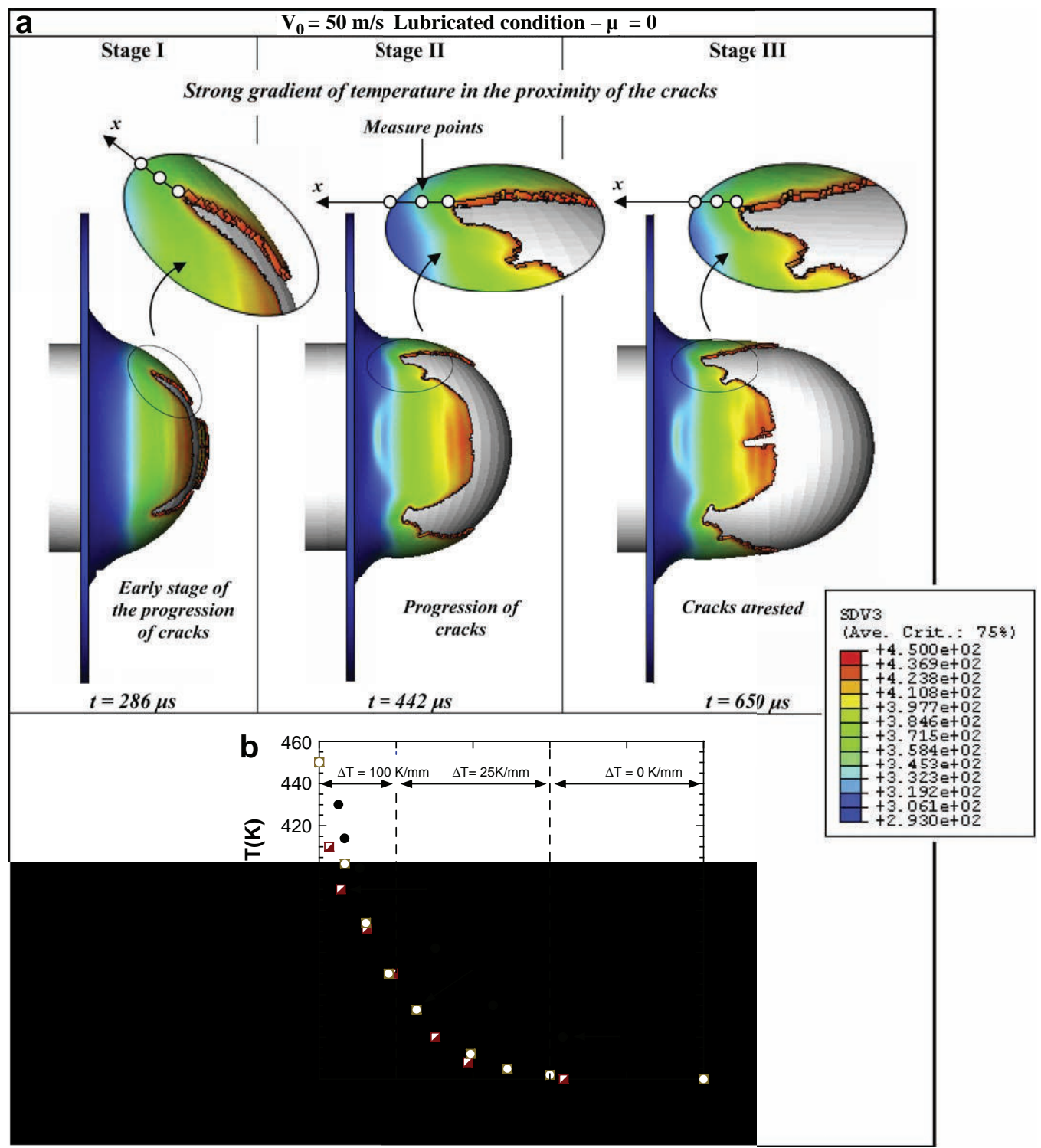

Fig. 26. (a) Temperature contours during petalling process [K]; (b) temperature values vs. distance from the bottom of the crack, simulation with RK constitutive relation. $V_{0} \quad 50 \mathrm{~m} / \mathrm{s}$; lubricated condition $-\mu \quad 0$.

differences appear on the failure mode depending on the condi tions of friction applied between the specimen and the projectile. Using dry conditions the failure process appears in the form of circumferential necking inducing plug ejection as final stage with reduced petalling. Whereas in the case of lubricated conditions the longer hole enlargement process is observed which induces a complete petal formation. At high impact velocities the differ ences between both conditions of friction are reduced and the plug ejection due to necking process is the common failure mode observed.

The influence of impact velocity on the failure mode, consid ering both conditions of friction, has been evaluated. In both cases the number of radial cracks increases with impact velocity. This phenomenon is induced by the increase of the circumferential strain level responsible of crack initiation and progression.

To evaluate the contribution of the particular energy compo nents involved in the process, an energy balance was carried out. From this analysis a conclusion may be drawn that the inertia effect increases as the impact velocity does, mainly due to the kinetic energy increase with the plug velocity. On the contrary, plastic work mainly governs the process for impact velocities close to the ballistic limit. For lubricated condition, plastic work represents almost $100 \%$ of the energy absorbed by the plate. When these conditions of friction and impact velocity are satisfied (ballistic limit velocity and lubricated condition) a complete petalling process is observed. The number and disposition of petals numer ically reproduced are in agreement with experimental observations and analytical predictions.

\section{Acknowledgements}

The researchers of the University Carlos III of Madrid are indebted to the Spanish Ministry of Education (project DPI2005 06769), and to the Region of Madrid (project CCG06 UC3M/DPI 0796) for the financial support that allowed to perform a part of the numerical simulations. The researchers from the Metz University (Laboratory of Physics and Mechanics of Materials) acknowledge ment some support by CNRS France. 


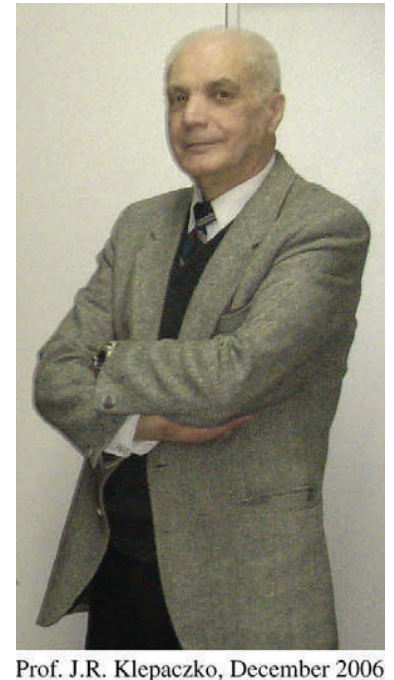

(Poznan University visit)

Janusz Roman Klepaczko passed away on August 15, 2008 at the age of 73. Graduated from Warsaw University of Technology in 1959, began the research work in 1960 at IPPT Institute of Fundamental Technological Research, Polish Academy of Sciences, Warsaw, Poland and continued it until 1984, becoming full professor in 1983. Since 1985 he was working in LPMM (Laboratory of Physic and Mechanic of Materials), Paul Verlaine University of Metz, France, where he was founder of the experimental laboratory. He was well known in the field of dynamic behavior of materials; he was the author of over 200 publications and supervised 30 doctors in several research centres around the world. Janusz was involved in research until the end of his life. He was a great researcher and had a passion for Science. He was for us a source of motivation and inspiration. We pay our tribute to him for his teaching and contribution in Science.

\section{Appendix A. Parameters of the mild steel for different constitutive relations}

\begin{tabular}{|c|c|c|}
\hline & $\begin{array}{l}\text { Johnson-Cook, set I } \\
\text { (low strain rates) }\end{array}$ & $\begin{array}{l}\text { Johnson-Cook, set I } \\
\text { (high strain rates) }\end{array}$ \\
\hline$\overline{A[\mathrm{MPa}]}$ & 57.27 & 57.27 \\
\hline$B[\mathrm{MPa}]$ & 479.93 & 79.641 \\
\hline$n[-]$ & 0.316 & 0.316 \\
\hline$C[-]$ & 0.0362 & 0.37848 \\
\hline$\varepsilon_{0}\left[\mathrm{~S}^{1}\right]$ & $10^{3}$ & $10^{3}$ \\
\hline$m[-]$ & 0.28 & 0.28 \\
\hline \multirow[t]{2}{*}{$T_{0}[\mathrm{~K}]$} & 300 & 300 \\
\hline & \multicolumn{2}{|c|}{ Rusinek-Klepaczko (low and high strain rates) } \\
\hline$B_{0}[\mathrm{MPa}]$ & \multicolumn{2}{|l|}{591.6} \\
\hline$n_{0}[-]$ & \multicolumn{2}{|l|}{0.285} \\
\hline$\varepsilon_{0}[-]$ & \multicolumn{2}{|l|}{$1.8 \times 10^{2}$} \\
\hline$D_{1}[-]$ & \multicolumn{2}{|l|}{0.48} \\
\hline$\nu[-]$ & \multicolumn{2}{|l|}{0.2} \\
\hline$\sigma_{0}^{*}[\mathrm{MPa}]$ & \multicolumn{2}{|l|}{406.3} \\
\hline$m[-]$ & \multicolumn{2}{|l|}{2.8} \\
\hline$D_{2}[-]$ & \multicolumn{2}{|l|}{0.19} \\
\hline$E_{0}[\mathrm{GPa}]$ & \multicolumn{2}{|l|}{212} \\
\hline$\vartheta^{*}[-]$ & \multicolumn{2}{|l|}{0.59} \\
\hline$T_{\mathrm{m}}[\mathrm{K}]$ & \multicolumn{2}{|l|}{1600} \\
\hline$\varepsilon_{\max }\left[\begin{array}{ll}S^{1}\end{array}\right]$ & \multicolumn{2}{|l|}{$10^{7}$} \\
\hline$\varepsilon_{\min }\left[\begin{array}{ll}\mathrm{S}^{1} & \end{array}\right]$ & \multicolumn{2}{|l|}{$10^{5}$} \\
\hline
\end{tabular}

Appendix A. (continued)

\begin{tabular}{|c|c|c|c|}
\hline \multirow{2}{*}{\multicolumn{2}{|c|}{$\begin{array}{l} \\
C_{p}\left[\mathrm{~J} \mathrm{~kg}^{1} \mathrm{~K}^{1}\right] \\
\beta[-] \\
\rho\left(\mathrm{kg} \mathrm{m}^{3}\right) \\
\alpha\left[\mathrm{K}^{1}\right]\end{array}$}} & \multicolumn{2}{|c|}{ Rusinek-Klepaczko (low and high strain rates) } \\
\hline & & $\begin{array}{l}470 \\
0.9 \\
7800 \\
10^{5}\end{array}$ & \\
\hline & $\begin{array}{l}\text { Power law, set I } \\
\text { (low strain rates) }\end{array}$ & & $\begin{array}{l}\text { Power law, set II } \\
\text { (high strain rates) }\end{array}$ \\
\hline $\bar{K}[\mathrm{MPa}]$ & 1598 & & 1598 \\
\hline$n[-]$ & 0.149 & & 0.149 \\
\hline$m[-]$ & 0.02 & & 0.062 \\
\hline$\nu[-]$ & 0.2 & & 0.2 \\
\hline
\end{tabular}

Appendix B. Relevant results of the numerical simulations

\begin{tabular}{|c|c|c|c|c|c|c|}
\hline $\begin{array}{l}\text { Impact } \\
\text { velocity, } \\
V_{0}[\mathrm{~m} / \mathrm{s}]\end{array}$ & $\begin{array}{l}\text { Residual } \\
\text { velocity, } \\
V_{0}[\mathrm{~m} / \mathrm{s}]\end{array}$ & $\begin{array}{l}\text { Work, } \\
W[J]\end{array}$ & $\begin{array}{l}\text { Plastic } \\
\text { work, } \\
W_{\mathrm{p}}[\mathrm{J}]\end{array}$ & $\begin{array}{l}\text { Failure } \\
\text { time, } \\
t_{\mathrm{f}}[\mu \mathrm{s}]\end{array}$ & $\begin{array}{l}\text { Plug } \\
\text { diameter, } \\
\Phi_{\mathrm{p}}[\mathrm{mm}]\end{array}$ & $\begin{array}{l}\text { Friction } \\
\text { coefficient } \\
\mu[-]\end{array}$ \\
\hline \multicolumn{7}{|l|}{$\overline{J C I}$} \\
\hline \multirow[t]{2}{*}{300} & 295.9 & 188.1 & 96.0 & 28 & 16.6 & 0.26 \\
\hline & 296.3 & 169.8 & 115.7 & 28 & 9.0 & 0 \\
\hline \multirow[t]{2}{*}{200} & 196.4 & 109.8 & 68.9 & 35 & 15.6 & 0.26 \\
\hline & 195.5 & 137.0 & 104.0 & 49 & 11.8 & 0 \\
\hline \multirow[t]{2}{*}{100} & 93.8 & 92.3 & 74.9 & 104 & 11.1 & 0.26 \\
\hline & 94.3 & 85.1 & 82.0 & 118 & 9.9 & 0 \\
\hline \multirow[t]{2}{*}{75} & 67.2 & 84.9 & 72.8 & 135 & 10.2 & 0.26 \\
\hline & 67.8 & 78.5 & 77.2 & 144 & 7.8 & 0 \\
\hline \multirow[t]{2}{*}{50} & - & - & - & - & - & 0.26 \\
\hline & - & - & - & - & - & 0 \\
\hline \multirow[t]{2}{*}{40} & - & - & - & - & - & 0.26 \\
\hline & - & - & - & - & - & 0 \\
\hline \multicolumn{7}{|l|}{ JCII } \\
\hline \multirow[t]{2}{*}{300} & 295.9 & 188.1 & 107.6 & 28 & 16.5 & 0.26 \\
\hline & 295.9 & 188.1 & 129.9 & 28 & 12.0 & 0 \\
\hline \multirow[t]{2}{*}{200} & 196.0 & 121.9 & 85.7 & 35 & 13.1 & 0.26 \\
\hline & 195.8 & 128.0 & 109.7 & 50 & 13.0 & 0 \\
\hline \multirow[t]{2}{*}{150} & 145.2 & 109.1 & 91.0 & 72 & 10.8 & 0.26 \\
\hline & 145.2 & 109.1 & 103.1 & 80 & 9.9 & 0 \\
\hline \multirow[t]{2}{*}{100} & 93.0 & 103.7 & 87.9 & 91 & 8.7 & 0.26 \\
\hline & 93.6 & 94.5 & 92.6 & 105 & 6.9 & 0 \\
\hline \multirow[t]{2}{*}{75} & 65.3 & 104.2 & 88.1 & 128 & 7.8 & 0.26 \\
\hline & 66.5 & 92.6 & 88.3 & 128 & 4.8 & 0 \\
\hline \multirow[t]{2}{*}{50} & 34.1 & 102.5 & 85.9 & 207 & 8.1 & 0.26 \\
\hline & 37.7 & 82.7 & 82.0 & 184 & 0 & 0 \\
\hline \multirow[t]{2}{*}{40} & 17.5 & 99.6 & 83.5 & 272 & 8.8 & 0.26 \\
\hline & 23.1 & 82.1 & 81.3 & 238 & 0 & 0 \\
\hline \multicolumn{7}{|l|}{$R K$} \\
\hline \multirow[t]{2}{*}{300} & 295.5 & 206.3 & 139.0 & 28 & 15.9 & 0.26 \\
\hline & 295.2 & 220.0 & 169.6 & 32 & 13.5 & 0 \\
\hline \multirow[t]{2}{*}{200} & 194.2 & 175.7 & 140.6 & 50 & 12.9 & 0.26 \\
\hline & 193.6 & 194.0 & 159.7 & 55 & 12.3 & 0 \\
\hline 150 & 143.1 & 157.9 & 132.5 & 70 & 11.4 & 0.26 \\
\hline & 143.3 & 151.3 & 144.0 & 84 & 10.2 & 0 \\
\hline 100 & 90.0 & 146.3 & 125.0 & 108 & 9.8 & 0.26 \\
\hline & 91.2 & 129.5 & 126.8 & 120 & 6.9 & 0 \\
\hline 80 & 67.4 & 142.7 & 123.0 & 145 & 9.9 & 0.26 \\
\hline & 69.3 & 123.0 & 120.5 & 150 & 5.7 & 0 \\
\hline 75 & 61.5 & 141.9 & 121.2 & 165 & 10 & 0.26 \\
\hline & 64.0 & 120.3 & 118.5 & 165 & 5.6 & 0 \\
\hline 50 & 27.8 & 133.0 & 112.9 & 250 & 10.5 & 0.26 \\
\hline & 32.1 & 113.1 & 111.7 & 250 & 0 & 0 \\
\hline 40 & 0 & 123.2 & 107.9 & 360 & - & 0.26 \\
\hline & 13.7 & 108.7 & 107.5 & 320 & 0 & 0 \\
\hline PLI & & & & & & \\
\hline 300 & 295.8 & 192.7 & 104.7 & 28 & 17.1 & 0.26 \\
\hline & 295.7 & 197.2 & 128.2 & 30 & 14.8 & 0 \\
\hline 200 & 196.1 & 118.9 & 87.4 & 40 & 14.8 & 0.26 \\
\hline & 194.9 & 155.0 & 116.9 & 54 & 14.5 & 0 \\
\hline 100 & 92.7 & 108.3 & 90.7 & 110 & 10.5 & 0.26 \\
\hline & 93.0 & 104.0 & 100.2 & 115 & 8.8 & 0 \\
\hline 75 & 65.0 & 107.8 & 91.7 & 154 & 12.5 & 0.26 \\
\hline & 66.0 & 97.7 & 95.3 & 168 & 10.4 & 0 \\
\hline
\end{tabular}




\begin{tabular}{|c|c|c|c|c|c|c|}
\hline $\begin{array}{l}\text { Impact } \\
\text { velocity, } \\
V_{0}[\mathrm{~m} / \mathrm{s}]\end{array}$ & $\begin{array}{l}\text { Residual } \\
\text { velocity, } \\
V_{0}[\mathrm{~m} / \mathrm{s}]\end{array}$ & $\begin{array}{l}\text { Work, } \\
W[\mathrm{~J}]\end{array}$ & $\begin{array}{l}\text { Plastic } \\
\text { work, } \\
W_{\mathrm{p}}[\mathrm{J}]\end{array}$ & $\begin{array}{l}\text { Failure } \\
\text { time, } \\
t_{\mathrm{f}}[\mu \mathrm{s}]\end{array}$ & $\begin{array}{l}\text { Plug } \\
\text { diameter, } \\
\Phi_{\mathrm{p}}[\mathrm{mm}]\end{array}$ & $\begin{array}{l}\text { Friction } \\
\text { coefficient } \\
\mu[-]\end{array}$ \\
\hline \multirow[t]{2}{*}{$\overline{50}$} & 38.6 & 77.8 & 85.0 & 220 & 10.5 & 0.26 \\
\hline & 37.0 & 86.9 & 91.0 & 240 & - & 0 \\
\hline \multirow[t]{2}{*}{40} & 17.7 & 99.0 & 84.1 & 310 & 10.2 & 0.26 \\
\hline & 20.5 & 90.8 & 89.4 & 320 & - & 0 \\
\hline \multicolumn{7}{|l|}{ PLII } \\
\hline \multirow[t]{2}{*}{300} & 293.8 & 283.5 & 219.4 & 42 & 13.9 & 0.26 \\
\hline & 293.3 & 306.0 & 219.5 & 42 & 12.0 & 0 \\
\hline \multirow[t]{2}{*}{200} & 194.4 & 170.0 & 155.2 & 50 & 13.0 & 0.26 \\
\hline & 191.2 & 265.0 & 177.9 & 60 & - & 0 \\
\hline \multirow[t]{2}{*}{100} & 88.0 & 173.7 & 149.2 & 130 & 10.8 & 0.26 \\
\hline & 89.6 & 151.8 & 148.4 & 124 & 7.5 & 0 \\
\hline \multirow[t]{2}{*}{75} & 59.0 & 165.1 & 140.3 & 165 & 11.4 & 0.26 \\
\hline & 61.6 & 140.7 & 139.0 & 170 & 5.8 & 0 \\
\hline \multirow[t]{2}{*}{50} & 22.1 & 154.9 & 133.5 & 270 & - & 0.26 \\
\hline & 28.0 & 62.8 & 130.6 & 255 & - & 0 \\
\hline \multirow[t]{2}{*}{40} & 0 & 123.2 & 114.0 & - & - & 0.26 \\
\hline & 0 & 123.2 & 121.0 & - & - & 0 \\
\hline
\end{tabular}

Appendix C. Elements eroded during the simulations

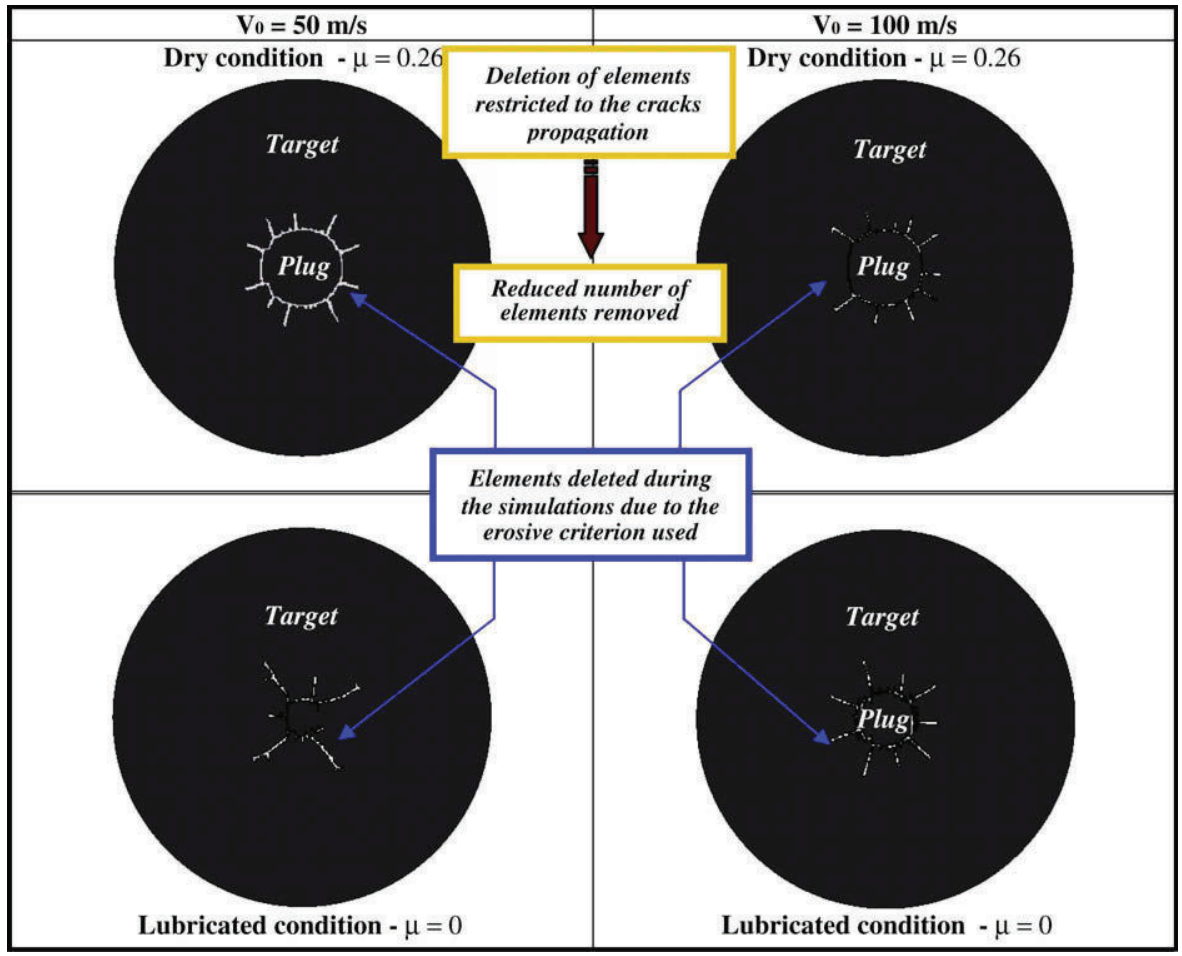

Fig C-1. Elements eroded during numerical simulations for both, lubricated and dry conditions for the case $V_{0} \quad 50 \mathrm{~m} / \mathrm{s}$ and $V_{0} \quad 100 \mathrm{~m} / \mathrm{s}$. 


\section{Appendix D. Influence of strain rate sensitivity on the plastic flow}

The explicit formulation of the JC constitutive relation without taking into account the term concerning the strain rate sensitivity is defined as follows:

$\bar{\sigma}\left(\bar{\varepsilon}^{\mathrm{p}}, \dot{\bar{\varepsilon}}^{\mathrm{p}}, T\right) \quad\left[A+B\left(\bar{\varepsilon}^{\mathrm{p}}\right)^{n}\right]\left(1 \quad \Theta^{m}\right)$

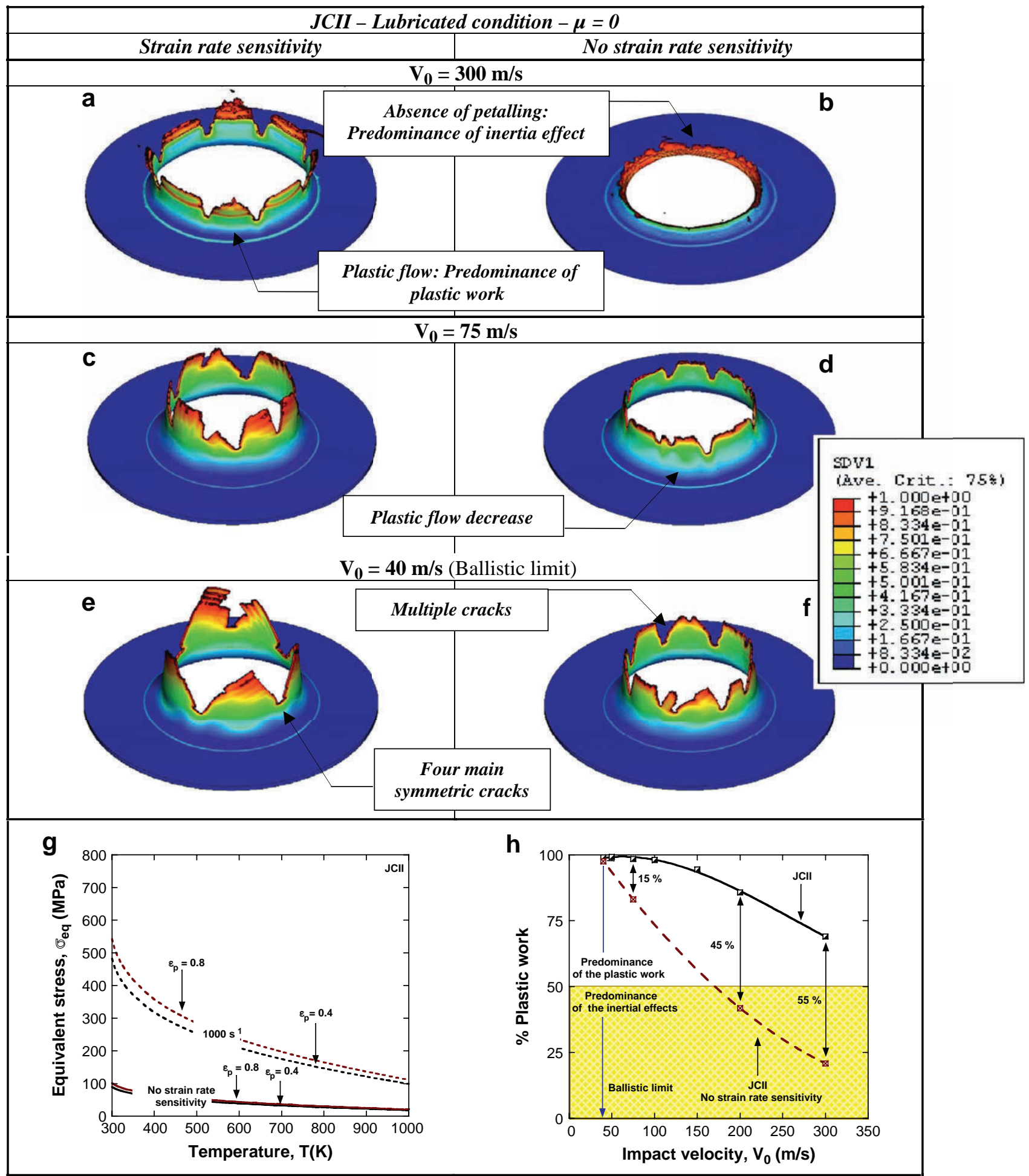

Fig. D-1. Equivalent plastic strain contours for JC constitutive relation with (a), (e), (g) and without (b), (f), (h) strain rate sensitivity at several impact velocities. (i) Equivalent stress vs. temperature and $(\mathrm{j}) \%$ plastic work for JC constitutive relation with and without strain rate sensitivity. 


\section{References}

[1] Campbell JD. The yield of mild steel under impact loading. J Mech Phys Solids 1954;3(1):54-62.

[2] Abramowicz W, Jones N. Dynamic axial crushing of square tubes. Int J Impact Eng 1984;2(2):179-208.

[3] Abramowicz W, Jones N. Dynamic axial crushing of circular tubes. Int J Impact Eng 1984;2(3):263-81.

[4] Thornton PH, Yeung KS. The dynamic buckling of sheet steel. Int J Impact Eng 1990;9(4):379-88

[5] Klepaczko JR. An experimental technique for shear testing at high and very high strain rates. The case of mild steel. Int J Impact Eng 1994;12(1):25-39.

[6] Li QM, Jones N. Response and failure of a double-shear beam subjected to mass impact. Int J Solids Struct 2002;39:1919-47.

[7] Teng X, Wierzbicki T, Hiermaier S, Rohr I. Numerical prediction of fracture in the Taylor test. Int J Solids Struct 2005;42:2929-48.

[8] Tarigopula V, Langseth M, Hopperstad OS, Clausen AH. Axial crushing of thin-walled high-strength steel sections. Int J Impact Eng 2006;32:847-82.

[9] Rusinek A, Zaera R. Finite element simulation of steel ring fragmentation under radial expansion. Int J Impact Eng 2007;34:799-822.

[10] Piekutowski AJ. Holes produced in thin aluminium sheets by the hypervelocity impact of aluminium spheres. Int J Impact Eng 1999;23:711-22.

[11] Forrestal MJ, Piekutowski AJ. Penetration experiments with 6061T6511aluminum targets and spherical-nose steel projectiles at striking velocities between 0.5 and $3.0 \mathrm{~km} / \mathrm{s}$. Int J Impact Eng 2000;24:57-67.

[12] Borvik T, Langseth M, Hoperstad OS, Malo KA. Perforation of $12 \mathrm{~mm}$ thick steel plates by $20 \mathrm{~mm}$ diameter projectiles with flat, hemispherical and conical noses part I: experimental study. Int I Impact Eng 2002;27(1):19-35.

[13] Borvik T, Langseth M, Hoperstad OS, Malo KA. Perforation of $12 \mathrm{~mm}$ thick stee plates by $20 \mathrm{~mm}$ diameter projectiles with flat, hemispherical and conica noses part II: numerical study. Int J Impact Eng 2002;27(1):37-64.

[14] Borvik T, Hoperstad OS, Langseth M, Malo KA. Effect of target thickness in blunt projectile penetration of Weldox $460 \mathrm{E}$ steel plates. Int J Impact Eng 2003;28:413-64.

[15] Gupta NK, Iqbal MA, Sekhon GS. Experimental and numerical studies on the behaviour of thin aluminium plates subjected to impact by blunt- and hemispherical-nosed projectiles. Int J Impact Eng 2006;32(12):1921-44.

[16] Gupta NK, Iqbal MA, Sekhon GS. Effect of projectile nose shape, impact velocity and target thickness on deformation behaviour of aluminium plates. Int J Solids Struct 2007;44(10):3411-39.

[17] Arias A, Rodríguez-Martínez JA, Rusinek A. Numerical simulations of impact behaviour of thin steel to cylindrical, conical and hemispherical nondeformable projectiles. Eng Fract Mech 2008;75:1635-56.

[18] Cheshire Eddie, Rossi Marco, Atkins Tony. Perforation of sheets by pyramidal weapons such as arrowheads. Int J Impact Eng 2008;35(6):457-70.

[19] Edwards MR, Mathewson A. The ballistic properties of tool steel as a potential improvised armour plate. Int J Impact Eng 1997;19(4):297-309.

[20] Atkins AG, Afzal Khan M, Liu JH. Necking and radial cracking around perforations in thin sheets at normal incidence. Int J Impact Eng 1998;21(7): 521-39.

[21] Wierzbicki T. Petalling of plates under explosive and impact loading. Int J Impact Eng 1999;22:935-54.

[22] Shen WQ, Rieve RO, Baharun B. A study on the failure of circular plates struck by masses. Part 1: experimental results. Int J Impact Eng 2002;27:399-412.

[23] Lee YW, Wierzbicki T. Fracture prediction of thin plates under localized impulsive loading. Part II: discing and petalling. Int J Impact Eng 2005;31: 1277-308.

[24] Piekutowski AJ. Debris clouds generated by hypervelocity impact of cylindrical projectiles with thin aluminium plates. Int J Impact Eng 1987;5(1-4):509-18.

[25] Cowper GR, Symonds PS. Strain hardening and strain rate effects in the impact loading of cantilever beams. Brown Univ., Div. of Appl. Mech., report no. 28; 1952.

[26] Bodner SR, Partom Y. Constitutive equations for elastic-viscoplastic strain-hardening materials. ASME J Appl Mech 1975;42:385-9.

[27] Steinberg DJ, Cochran SG, Guinan MW. Constitutive model for metals applicable at high strain rates. J Appl Phys 1980;51(3):1498-504.

[28] Nemat-Nasser S. On finite deformation elastoplasticity. Int J Solids Struct 1982;18:857-72.

[29] Johnson GR, Cook WH. A constitutive model and data for metals subjected to large strains, high strain rates and high temperatures. In: Proceedings of 7th international symposium on ballistics; 1983. p. 541-7.

[30] Zerilli FJ, Armstrong RW. Dislocation-mechanics-based constitutive relations for material dynamics calculations. J Appl Phys 1987;61:1816-25.

[31] Khan A. Continuum theory of plasticity. New York: Wiley; 1998 [Chapter 8].

[32] Rusinek A, Klepaczko JR. Shear testing of sheet steel at wide range of strain rates and a constitutive relation with strain-rate and temperature dependence of the flow stress. Int J Plasticity 2001;17:87-115.

[33] Liang R, Khan AS. A critical review of experimental results and constitutive models for BCC and FCC metals over a wide range of strain rates and temperatures. Int J Plasticity 1999;15:963-80.

[34] Rusinek A, Zaera R, Klepaczko JR. Constitutive relations in 3-D for a wide range of strain rates and temperatures - application to mild steels. Int J Solids Struct 2007;44:5611-34.

[35] Boumaaiz H, Klepaczko JR. Punching by impact, case of mild steel. DYMAT Journal 1995;2(1):13-29 [in French].
[36] Klepaczko JR. A practical stress-strain-strain rate-temperature constitutive relation of the power form. J Mech Work Technol 1987;15:143-65.

[37] Rusinek A. Modélisation thermoviscoplastique d'une nuance de tôle d'acier aux grandes vitesses de déformation. Etude expérimentale et numérique du cisaillement, de la traction et de la perforation. Ph.D. thesis, Université du Metz; 2000.

[38] Segreti M, Rusinek A, Klepaczko JR. Experimental study on puncture of PMMA at low and high velocities, effect on the failure mode. Polym Test 2004;23: 703-18.

[39] Klepaczko JR. Displacement gauge with a photodiode. Measurements, Automatics and Control 1966:12:466-76 [in Polish].

[40] Marsh KJ, Campbell JD. The effect of strain rate on the post-yield flow of mild steel. J Mech Phys Solids 1963;11(1):49-52.

[41] Bonorchis D, Nurick GN. The effect of welded boundaries on the response of rectangular hot-rolled mild steel plates subjected to localised blast loading. Int J Impact Eng 2007;34:1729-38.

[42] Borvik T, Langseth M, Hopperstad OS, Malo KA. Ballistic penetration of steel plates. Int J Impact Eng 1999;22:855-86.

[43] Smerd R, Winkler S, Salisbury C, Worswick M, Lloyd D, Finn M. High strain rate tensile testing of automotive aluminium alloy sheet. Int J Impact Eng 2005;32: 541-60.

[44] Kobayashi T, Simons JW, Brown CS, Shockey DA. Plastic flow behaviour of Inconel 718 under dynamic shear loads. Int J Impact Eng 2008;35(5): 389-96.

[45] Johnson GR, Holmquist TJ, Anderson Jr CE, Nicholls AE. Strain-rate effects for high-strain rate computations. J Phys IV France 2006;134:391-6.

[46] Klepaczko JR. Thermally activated flow and strain rate history effects for some polycrystalline FCC metals. Mater Sci Eng 1975;18:121-35.

[47] Klepaczko JR. A general approach to rate sensitivity and constitutive modeling of FCC and BCC metals. In: Impact: effects of fast transient loadings. Rotterdam: A.A. Balkema; 1998. p. 3-35.

[48] Quinney H, Taylor GI. The emission of latent energy due to previous cold working when a metal is heated. Proc R Soc London 1937;163:157-81.

[49] Oussouaddi O, Klepaczko JR. An analysis of transition from isothermal to adiabatic deformation in the case of a tube under torsionProceedings. conf. DYMAT 91. Journal de Physique IV 1991;Coll. C3(Suppl. III):C3-323 [in French]

[50] Rusinek A, Zaera R, Klepaczko JR, Cheriguenne R. Analysis of inertia and scale effects on dynamic neck formation during tension of sheet steel. Acta Mater 2005;53:5387-5400

[51] Zaera R, Fernández-Sáez J. An implicit consistent algorithm for the integration of thermoviscoplastic constitutive equations in adiabatic conditions and finite deformations. Int J Solids Struct 2006;43:1594-1612.

[52] Wood WW. Experimental mechanics at velocity extremes - very high strain rates. Exp Mech 1965;5:361-371.

[53] Teng X, Wierzbicki T. Evaluation of six fracture models in high velocity perforation. Eng Fract Mech 2006;73(12):1653-1678.

[54] Considère M. L'emploi du fer de l'acier dans les constructions. Mémoire no 34. Annales des Ponts et Chaussées, Paris 1885:574-575.

[55] Triantafyllidis N, Waldenmyer JR. Onset of necking in electro-magnetically formed rings. J Mech Phys Solids 2004;52:2127-2148.

[56] Pandolfi A, Krysl P, Ortiz M. Finite element simulation of ring expansion and fragmentation. Int J Fract 1999;95:279-297.

[57] Singh M, Suneja HR, Bola MS, Prakash S. Dynamic tensile deformation and fracture of metal cylinders at high strain rates. Int J Impact Eng 2002;27:939-954.

[58] Law M. Use the cylindrical instability stress for blunt metal loss defects in linepipe. Int J Press Vessels Pip 2005;82(12):925-928.

[59] Rincón E, López HF, Cisneros MM. Effect of temperature on tensile properties of an as-cast aluminum alloy A319. Mater Sci Eng A 2007;15:682-687.

[60] Colombo D, Giglio M. Numerical analysis of thin-walled shaft perforation by projectile. Comput Struct 2007;85:1264-1280.

[61] Børvik T, Clausen AH, Eriksson M, Berstad T, Hopperstad OS, Langseth M. Experimental and numerical study on the perforation of AA6005-T6 panels. Int J Impact Eng 2005;32:35-64.

[62] Rusinek A, Arias A, Rodríguez-Martínez JA, Klepaczko JR, López-Puente J. Influence of conical projectile diameter on perpendicular impact of thin steel plate. Eng Fract Mech 2008;75:2946-2967.

[63] Philippon S, Sutter G, Garcin F. Dynamic analysis of the interaction between an abradable material and a titanium alloy. Wear 2006;261(5):686-692.

[64] Voyiadjis GZ, Abu Al-Rub RKA. Finite strain plastic-damage model for high velocity impacts using combined viscosity and gradient localization limiters: part II - numerical aspects and simulations. Int J Damage Mech 2006;15: 335-373.

[65] Gupta NK, Iqbal MA, Sekhon GS. Effect of projectile nose shape, impact velocity and target thickness on the deformation behaviour of layered plates. Int J Impact Eng 2008;35(1):37-60.

[66] Teng X, Wierzbicki, Couque H. On the transition from adiabatic shear banding to fracture. Mech Mater 2007;39:107-125.

[67] Hibbitt HD, Karlsson BI, Sorensen P. Abaqus user's manual. ABAQUS/EXPLICIT $6.5 ; 2005$.

[68] Rusinek A, Klepaczko JR. A numerical study on the wave propagation in tensile and perforation test. J Phys IV 2000;10:653-658.

[69] Rusinek A, Klepaczko JR. A viscoplastic modeling of sheet metal in the range of large deformation and at low and high strain rates: application to perforation. Z Angew Math Mech 2000;3(80):S601-2.

[70] Lee M. Cavitation and mushrooming in attack of thick targets by deforming rods. J Appl Mech 2001;68:420-4 
[71] Taylor GI. The formation of enlargement of circular holes in thin plastic plates. Q J Mech Appl Math 1948;1:103-24.

[72] Zaid M, Paul B. Mechanics of high speed projectile perforation. J Franklin Inst 1958;265:317-35

[73] Paul B, Zaid M. Normal perforation of a thin plate by truncated projectiles. J Franklin Inst 1957:264:117-26.

[74] Johnson W, Chitkara NR, Ibrahim AH, Dasgupta AK. Hole flanging and punching of circular plates with conically headed cylindrical punches. J Strain Anal 1973;8(3):228-41.

[75] Landkof B, Goldsmith W. Petalling of thin, metallic plates during penetration by cylindro-conical projectiles. Int J Solids Struct 1993;21:245-66.

[76] Batra RC, Wei ZC. Instability strain and shear band spacing in simple tensile/compressive deformations of thermoviscoplastic materials. Int J Impact Eng 2007;34:448-63.
[77] Batra RC, Chen L. Effect of viscoplastic relations on the instability strain, shea band initiation strain, the strain corresponding to the minimum shear band spacing, and the band width in a thermoviscoplastic material. Int J Plasticity 2001;17:1465-89.

[78] Alos S, Hopperstad OS, Tomquist R, Amdahl J. Analytical and numerical analysis of sheet metal instability sing a stress based criterion. Int J Solids Struct 2008;45:2042-55.

[79] Kuroda M, Uenishi A, Yoshida H, Igarashi A. Ductility of interstitial-free steel under high strain rate tension: experiments and macroscopic modelling with a physically-based consideration. Int J Solids Struct 2006; 43:4465-83.

[80] Rusinek A, Rodríguez-Martínez JA, Klepaczko JR, Pecherski RB. Analysis of thermo-visco-plastic behaviour of six high strength steels. J Mater Design 2008d;. doi:10.1016/j.matdes.2008.07.034 